\title{
Spirotrichilins A and B: Two Rearranged Spirocyclic Limonoids from Trichilia connaroides
}

\author{
Fa-Liang An, ${ }^{\dagger}$ Jun Luo, ${ }^{\dagger}$ Rui-Jun Li, Jian-Guang Luo, Xiao-Bing Wang, \\ Ming-Hua Yang, Lei Yang, He-Quan Yao, Hong-Bin Sun, Yi-Jun Chen and \\ Ling-Yi Kong* \\ State Key Laboratory of Natural Medicines, Department of Natural Medicinal Chemistry, China \\ Pharmaceutical University, 24 Tong Jia Xiang, Nanjing 2100o9, People's Republic of China \\ Supporting Information Placeholder
}




\section{Supporting Information}

\section{Table of Contents}

\section{Experimental section}

1.1 General Experimental Procedures.

1.2 Plant Material.

1.3 Extraction and Isolation

1.4 Computational Section

$1.5 \mathrm{NO}$ production bioassay

\section{NMR, HRESIMS, UV and ECD Spectra}

S1. ${ }^{1} \mathrm{H}$ NMR ( $500 \mathrm{MHz}$; MeOD- $\left.d_{4}\right)$ spectrum of $\mathbf{1}$.

S2. ${ }^{13} \mathrm{C}$ NMR (125 MHz; MeOD- $\left.d_{4}\right)$ spectrum of $\mathbf{1}$.

S3. HSQC (MeOD- $\left.d_{4}\right)$ spectrum of $\mathbf{1}$.

S4. HMBC (MeOD- $\left.d_{4}\right)$ spectrum of 1 .

S5. ROESY (MeOD- $\left.d_{4}\right)$ spectrum of $\mathbf{1}$.

S6. ${ }^{1} \mathrm{H}$ NMR (500 MHz; DMSO- $\left.d_{6}\right)$ spectrum of $\mathbf{1}$.

S7. ${ }^{13} \mathrm{C}$ NMR (125 MHz; DMSO- $\left.d_{6}\right)$ spectrum of $\mathbf{1}$.

S8. HSQC (DMSO- $d_{6}$ ) spectrum of 1.

S9. HMBC (DMSO- $\left.d_{6}\right)$ spectrum of $\mathbf{1}$.

S10. ROESY (DMSO- $d_{6}$ ) spectrum of $\mathbf{1}$.

S11. HRESIMS of 1.

S12. UV spectrum of $\mathbf{1}$.

S13. ${ }^{1} \mathrm{H}$ NMR (500 MHz; $\mathrm{CDCl}_{3}$ ) spectrum of 2.

S14. ${ }^{13} \mathrm{C}$ NMR $\left(125 \mathrm{MHz} ; \mathrm{CDCl}_{3}\right)$ spectrum of 2.

$\mathrm{S} 15$. HSQC $\left(\mathrm{CDCl}_{3}\right)$ spectrum of 2.

$\mathrm{S} 16 . \mathrm{HMBC}\left(\mathrm{CDCl}_{3}\right)$ spectrum of 2.

S17. ROESY $\left(\mathrm{CDCl}_{3}\right)$ spectrum of $\mathbf{2}$.

S18. ${ }^{1} \mathrm{H}$ NMR (500 MHz; Acetone- $\left.d_{6}\right)$ spectrum of 2.

S19. ${ }^{13} \mathrm{C}$ NMR (125 MHz; Acetone- $d_{6}$ ) spectrum of 2.

S20. HSQC (Acetone- $d_{6}$ ) spectrum of 2.

S21. HMBC (Acetone- $d_{6}$ ) spectrum of 2.

S22. ROESY (Acetone- $d_{6}$ ) spectrum of 2.

S23. HRESIMS of 2.

S24. UV spectrum of 2.

S25. Table 1. ${ }^{1} \mathrm{H}(500 \mathrm{MHz})$ and ${ }^{13} \mathrm{C}(125 \mathrm{MHz})$ NMR Data of Compounds 1-2.

S26 ECD spectra of $\mathbf{1}$ and $\mathbf{2}$.

S27 Selected conformer for the calculation of ECD data of 1 (in $\mathrm{MeOH}$ ).

S28. Calculated ECD and experimental ECD spectra of $\mathbf{1 .}$

S29. Calculated UV and experimental UV spectra spectrum of $\mathbf{1}$.

S30. Energies of the conformers with Boltzmann distribution over $1 \%$. 
S31 Energies and vibrational analysis of compounds 1. 


\section{EXPERIMENTAL SECTION}

1.1 General Experimental Procedures. Optical rotations were measured on a JASCO $\mathrm{P}-1020$ polarimeter in $\mathrm{MeOH}$ at room temperature. Nuclear magnetic resonance (NMR) spectra were on a Bruker AVIII-500 NMR instrument $\left({ }^{1} \mathrm{H}: 500 \mathrm{MHz},{ }^{13} \mathrm{C}: 125\right.$ MHz) (Bruker, Karlsruhe, Germany), with tetramethylsilane (TMS) as an internal standard. Chemical shift values $(\delta)$ are given in parts per million (ppm) and coupling constants in Hertz $(\mathrm{Hz})$. The following abbreviations are used to designate multiplicities: $\mathrm{s}=$ singlet, $\mathrm{d}=$ doublet, $\mathrm{t}=$ triplet, $\mathrm{m}=$ multiplet, $\mathrm{br}=$ broad. Electrospray ionization (ESI) and high-resolution electrospray ionization (HRESIMS) were carried out an Agilent 1100 series LC/MSD ion trap mass spectrometer and an Agilent 6529B Q-TOF instrument (Agilent Technologies, Santa Clara, CA, USA), respectively. ECD data were recorded on a Jasco spectrometer (Jasco, Tokyo, Japan). Preparative high-performance liquid chromatography (Pre-HPLC) was performed on a Shimadzu LC-6A system (Shimadzu, Tokyo, Japan) equipped with a Shim-pack RP-C 18 column $(200 \mathrm{~mm} \times 20 \mathrm{~mm}$ i.d., $10 \mu \mathrm{m}$, Shimadzu, Tokyo, Japan $)$ with flow rate at $10.0 \mathrm{ml} / \mathrm{min}$ and column temperature at $25{ }^{\circ} \mathrm{C}$, detected by a binary channel UV detector at 210 and $230 \mathrm{~nm}$. All solvents used were of analytical grade (Jiangsu Hanbang Science and Technology. Co., Ltd.). Silica gel (200-300 mesh, Qingdao Haiyang Chemical Co., Ltd, Qingdao China), MCI (Mitsubishi, Japan) and RP-C 18 silica (40-63 $\mu \mathrm{m}, \mathrm{FuJi}$, Japan) were used for column chromatography. Fractions obtained from column chromatography (CC) were monitored by thin-layer chromatography (TLC) with precoated silica gel $\mathrm{GF}_{254}$ (Qingdao Haiyang Chemical 
Co., Ltd, China) plates.

1.2 Plant Material. Air-dried fruits of Trichilia connaroides were collected from Xishuangbanna, Yunnan Province, People's Republic of China, in June 2014, and were authenticated by Professor Shun-Cheng Zhang, Xishuangbanna Tropical Botanical Garden, Chinese Academy of Sciences, People's Republic of China. A voucher specimen was deposited in the Department of Natural Medicinal Chemistry, China Pharmaceutical University (accession number AA201308).

\subsection{Extraction and isolation.}

The dried powder of fruits of T. connaroides $(5.0 \mathrm{~kg})$ was extracted three times $(3 \times$ 5L) with $95 \% \mathrm{EtOH}$, and the crude (500 g) was suspended in $\mathrm{H}_{2} \mathrm{O}$ and extracted with petroleum ether $(\mathrm{PE})(3 \times 1 \mathrm{~L})$ and EtOAc $(3 \times 1 \mathrm{~L})$, successively. The ethyl acetate extract (100.0 g) was subjected to a silica gel column, eluted with $\mathrm{CH}_{2} \mathrm{Cl}_{2}-\mathrm{MeOH}$ $(100: 1,50: 1,25: 1,10: 1,5: 1, \mathrm{v} / \mathrm{v})$ to give five fractions (A1-A5). Fraction A4 (12.5 g) was chromatographed over a middle chromatogram isolated (MCI) column eluted with a gradient system of $\mathrm{MeOH}-\mathrm{H}_{2} \mathrm{O}(50: 5,75: 25,95: 5, v / v)$ to give three fractions (A4A-A4C), respectively. A4B (5.0 g) was sequentially fractionated over columns of RP-18 silica gel $\left(\mathrm{MeOH}-\mathrm{H}_{2} \mathrm{O}, 50 \%\right.$ to $\left.75 \%, v / v\right)$ to obtain two precious components, which were further purified by pre-HPLC $\left(65 \% \mathrm{MeOH}-\mathrm{H}_{2} \mathrm{O}, v / v\right)$ to afford compounds $\mathbf{1}(6.0 \mathrm{mg})$ and $\mathbf{2}(2.0 \mathrm{mg})$, respectively.

\subsection{Computational Section}

The calculation of ECD have been an important method in determining the absolute configurations of natural chiral compounds. Systematic conformation analyses for 
compound 1 were applied via Confab using the MMFF94 force field calculation. Conformers with Boltzmann distribution over $1 \%$ were chosen as the beginning for ECD calculations and only one conformer was chosen for compound 1 (S27). Ground-state geometries were optimized at B3LYP/6-311G** level by the Gaussian09 program package and vibrational analysis was done to confirm these minima. the Self-Consistent Reaction Field method (SCRF) with the C-Polarizable Continuum Model (CPCM) was further employed to perform the conformational analysis and ECD calculation in methanol solution at B3LYP/6-311G** level. The theoretical ECD spectra was obtained without the Boltzmann weighting based on only one suitable conformer proved by systematic conformation analyses. Comparisons of the experimental and calculated spectra were carried out using SpecDis with UV shift $(-12 \mathrm{~nm})$ and a half-bandwidth of $0.29 \mathrm{eV}$. The absolute configurations of 1 were assigned as $1 R, 2 R, 5 S, 6 R, 8 S, 10 S, 11 R, 13 R, 14 E$, and $17 R$, respectively.

\subsection{NO production bioassay}

The RAW264.7 cell line was purchased from the Chinese Academic of Sciences. The cells were cultured in DMEM containing 10\% FBS with penicillin $(100 \mathrm{U} / \mathrm{mL})$ and streptomycin $(100 \mathrm{U} / \mathrm{mL})$ at $37{ }^{\circ} \mathrm{C}$ in a humidified atmosphere with $5 \% \mathrm{CO}$. The cells were allowed to grow in 96 -well plates with $1 \times 105$ cells/ well to treat test compounds. After being incubated for $2 \mathrm{~h}$, the cells were treated with $100 \mathrm{ng} / \mathrm{mL}$ of LPS for $18 \mathrm{~h}$. Nitrite in culture media was measured to assess NO production using Griess reagent. The absorbance at 540nm was measured on a microplate reader. N-monomethyl-L-arginine was used as the positive control. Cytotoxicity was 
determined by the MTT method, after $48 \mathrm{~h}$ incubation with test compounds. All the experiments were performed in three independent replicates.

Spirotrichilin A (1): white powder, $[\alpha]_{\mathrm{D}}^{23}+65.4(c, 0.39, \mathrm{MeOH})$; UV $(\mathrm{MeOH}) \lambda_{\max }$ $209 \mathrm{~nm} ;{ }^{1} \mathrm{H}$ and ${ }^{13} \mathrm{C}$ NMR (MeOD- $d_{4}, \mathrm{DMSO}-d_{6}$ ), see Table 1 and S25; negative ESIMS $m / z 611.0\left[\mathrm{M}+\mathrm{Cl}^{-}\right.$; positive ESIMS $m / z$ 577.1 $[\mathrm{M}+\mathrm{H}]^{+} ;$HRESIMS $m / z$ 599.1737 [M $+\mathrm{Na}]^{+}$(calcd for $\mathrm{C}_{28} \mathrm{H}_{32} \mathrm{O}_{13} \mathrm{Na}, 599.1735$ ).

Spirotrichilin B (2): white powder, $[\alpha]_{\mathrm{D}}^{23}+67.5(c, 0.30, \mathrm{MeOH})$; UV $(\mathrm{MeOH}) \lambda_{\max }$ $207 \mathrm{~nm} ;{ }^{1} \mathrm{H}$ and ${ }^{13} \mathrm{C}$ NMR (MeOD- $d_{4}$, Acetone- $d_{6}$ ), see Table 1 and S25; positive ESIMS $m / z 517.2[\mathrm{M}+\mathrm{H}]^{+}$; HRESIMS $m / z 539.1527[\mathrm{M}+\mathrm{Na}]^{+}$(calcd for $\left.\mathrm{C}_{26} \mathrm{H}_{28} \mathrm{O}_{11} \mathrm{Na}, 539.1524\right)$.

\section{NMR, HRESIMS, and UV Spectra}

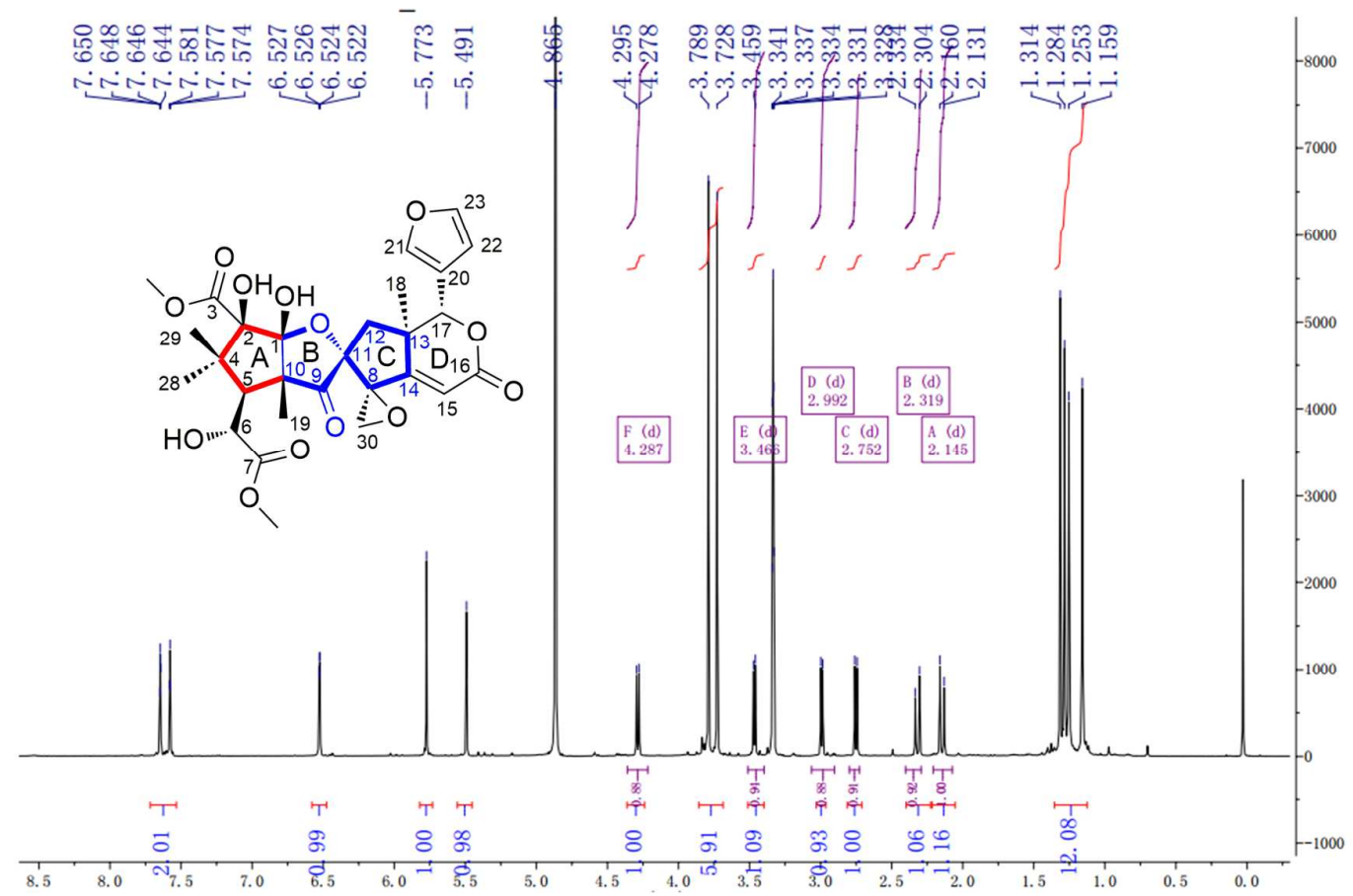

S1. ${ }^{1} \mathrm{H}$ NMR (500 MHz; MeOD- $\left.d_{4}\right)$ spectrum of 1. 


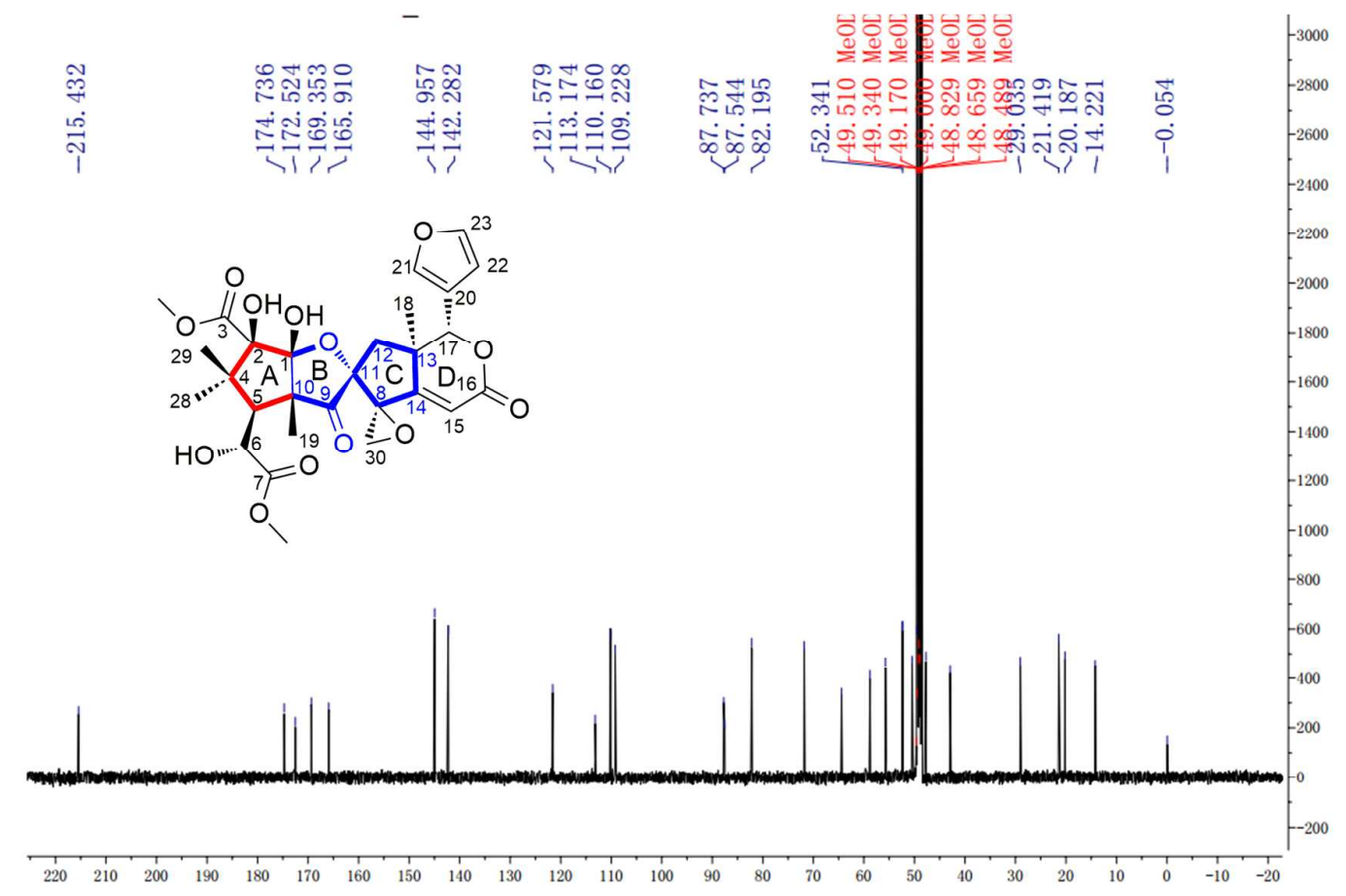

S2. ${ }^{13} \mathrm{C}$ NMR (125 MHz; MeOD- $\left.d_{4}\right)$ spectrum of $\mathbf{1}$.

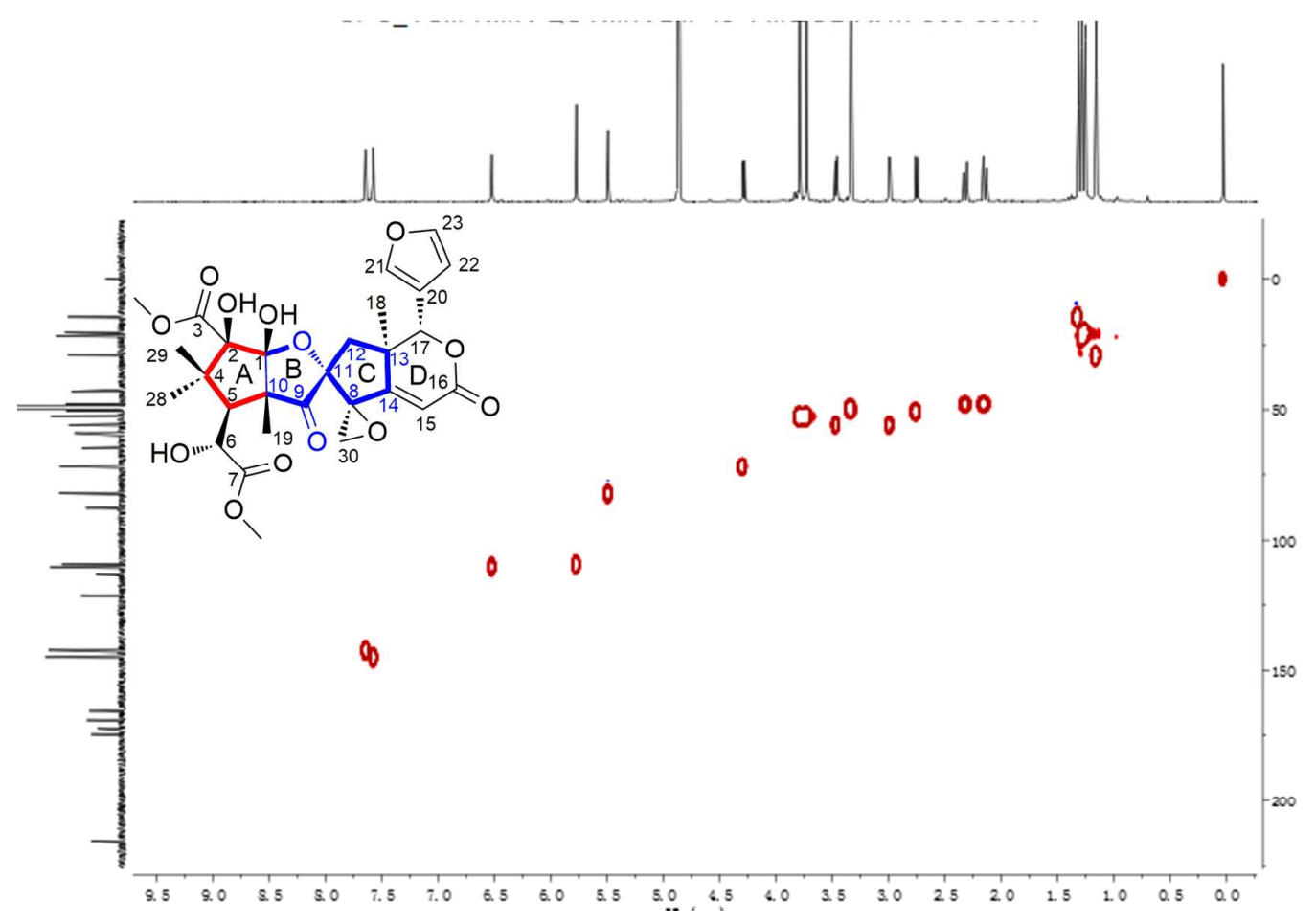

S3. HSQC (MeOD- $\left.d_{4}\right)$ spectrum of $\mathbf{1}$. 


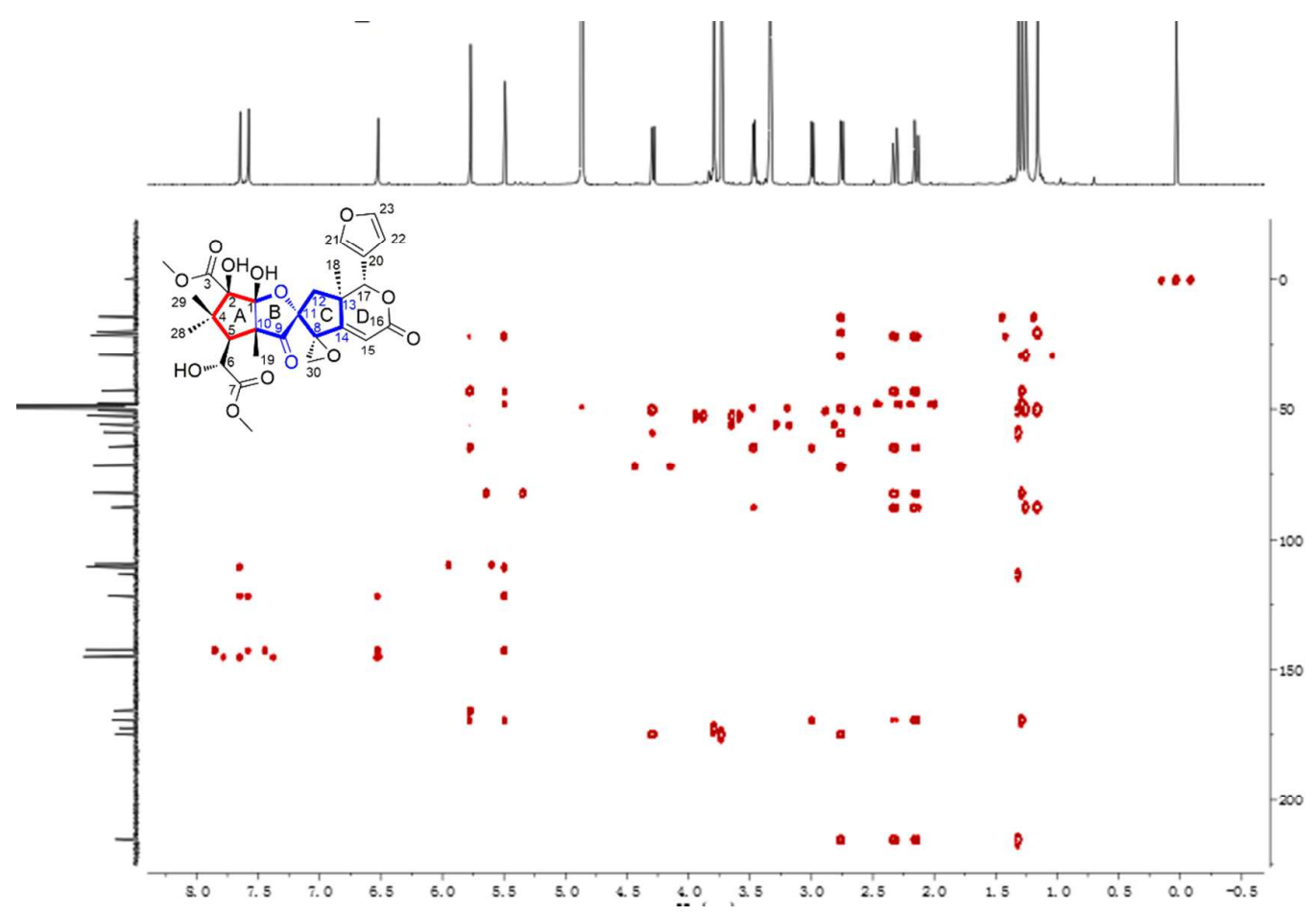

S4. HMBC (MeOD- $\left.d_{4}\right)$ spectrum of $\mathbf{1}$.

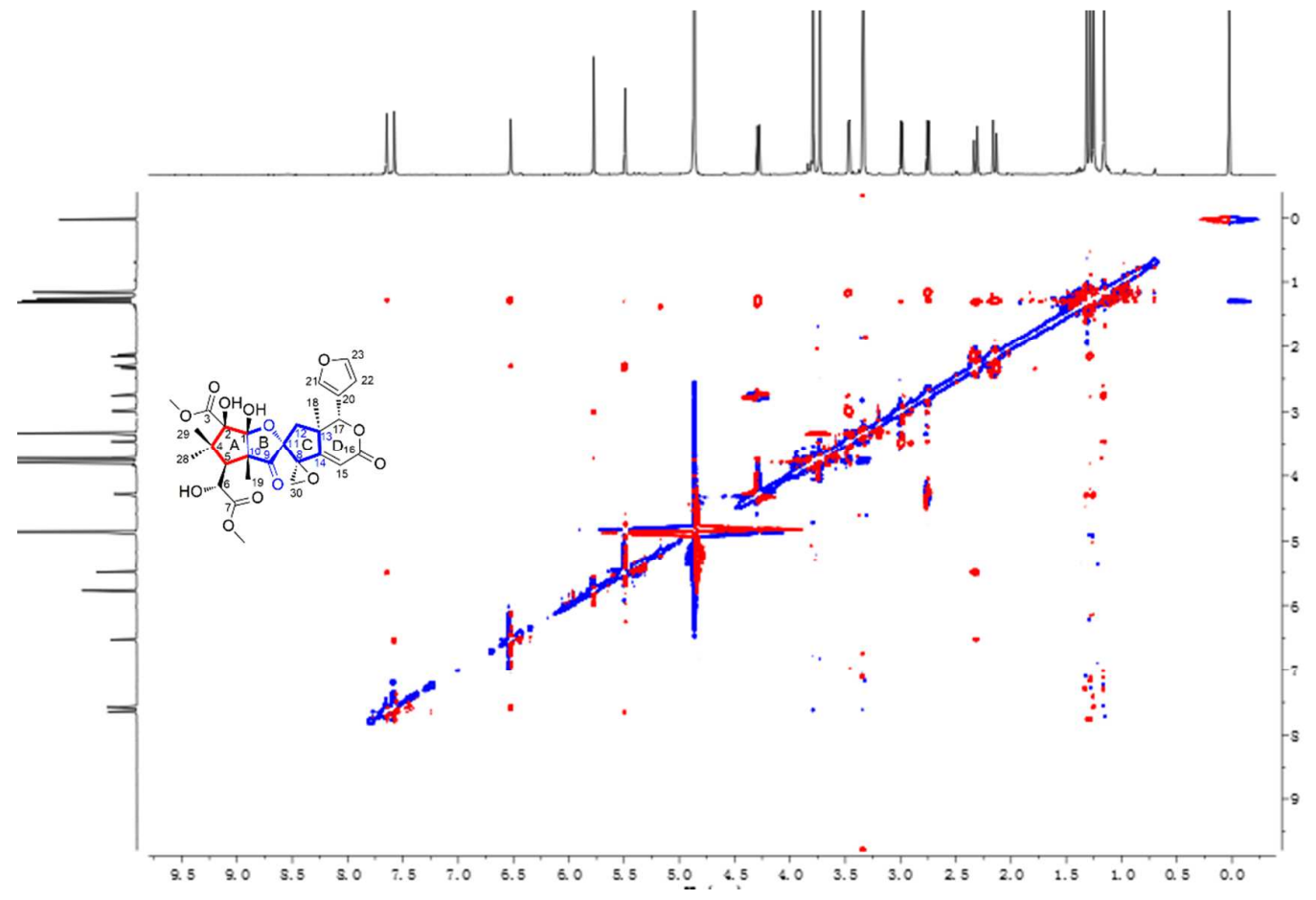

S5. ROESY (MeOD- $\left.d_{4}\right)$ spectrum of $\mathbf{1}$. 


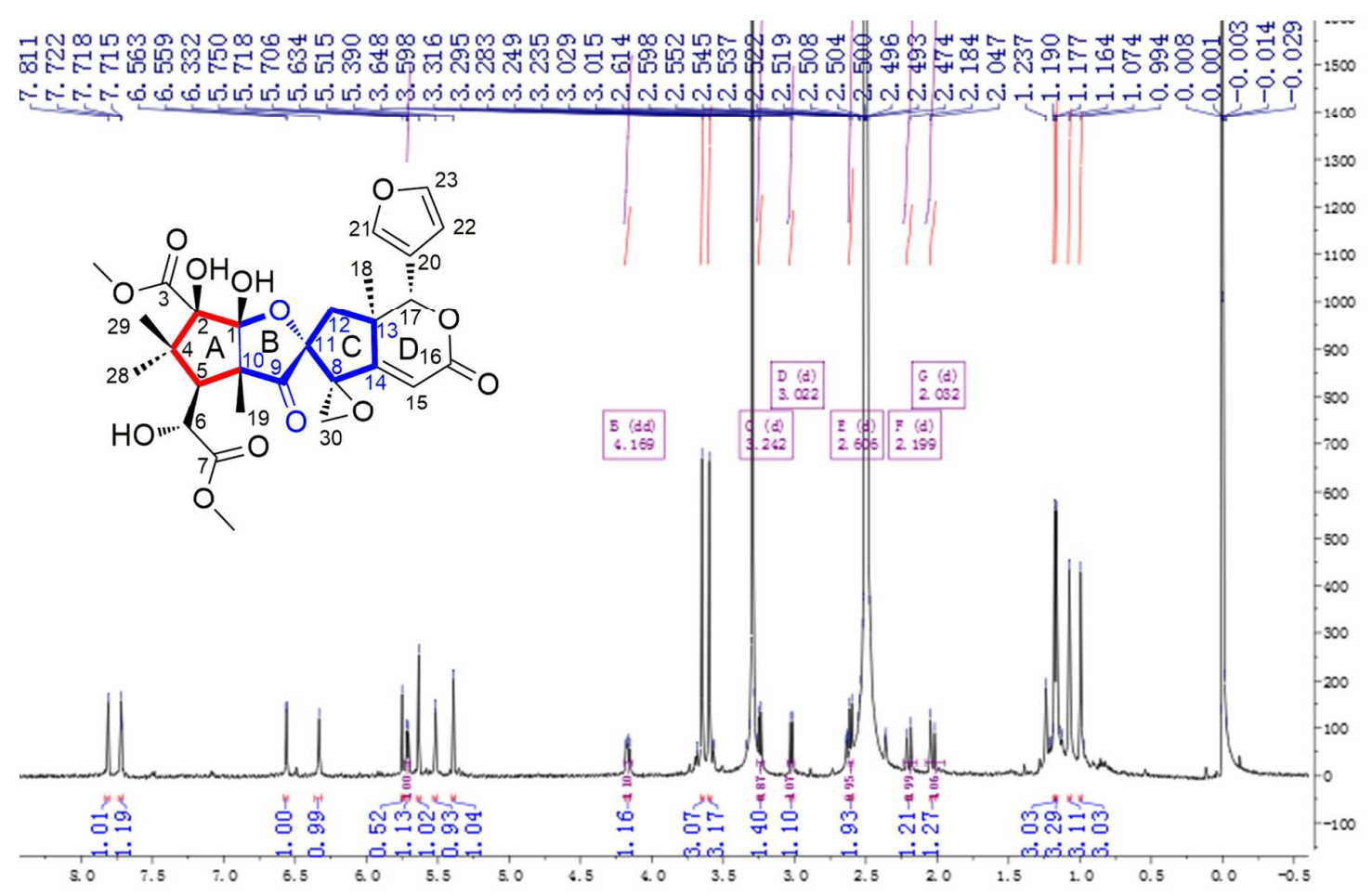

S6. ${ }^{1} \mathrm{H}$ NMR (500 MHz; DMSO- $d_{6}$ ) spectrum of $\mathbf{1}$.

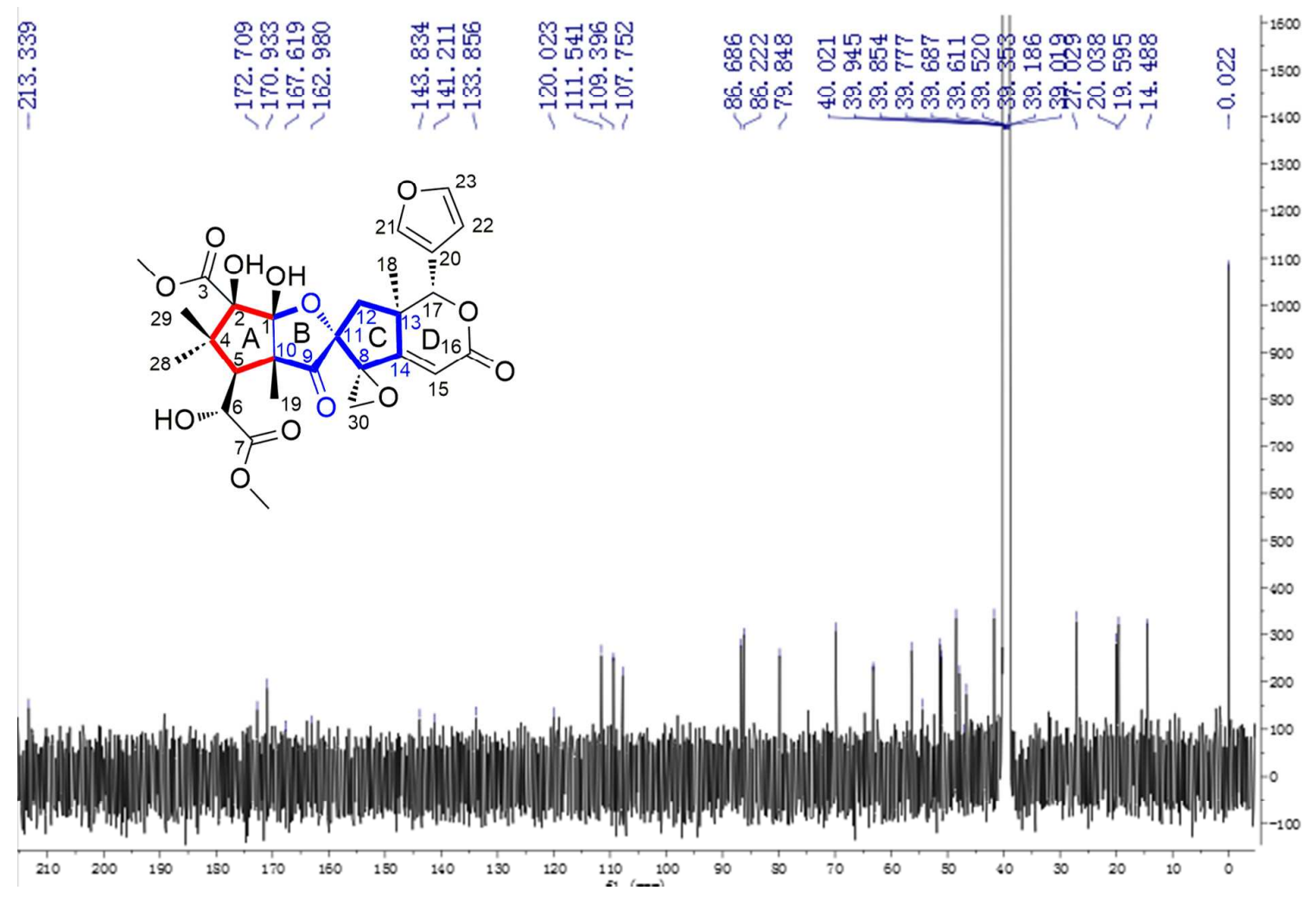

S7. ${ }^{13} \mathrm{C}$ NMR (125 MHz; DMSO- $d_{6}$ ) spectrum of $\mathbf{1}$. 


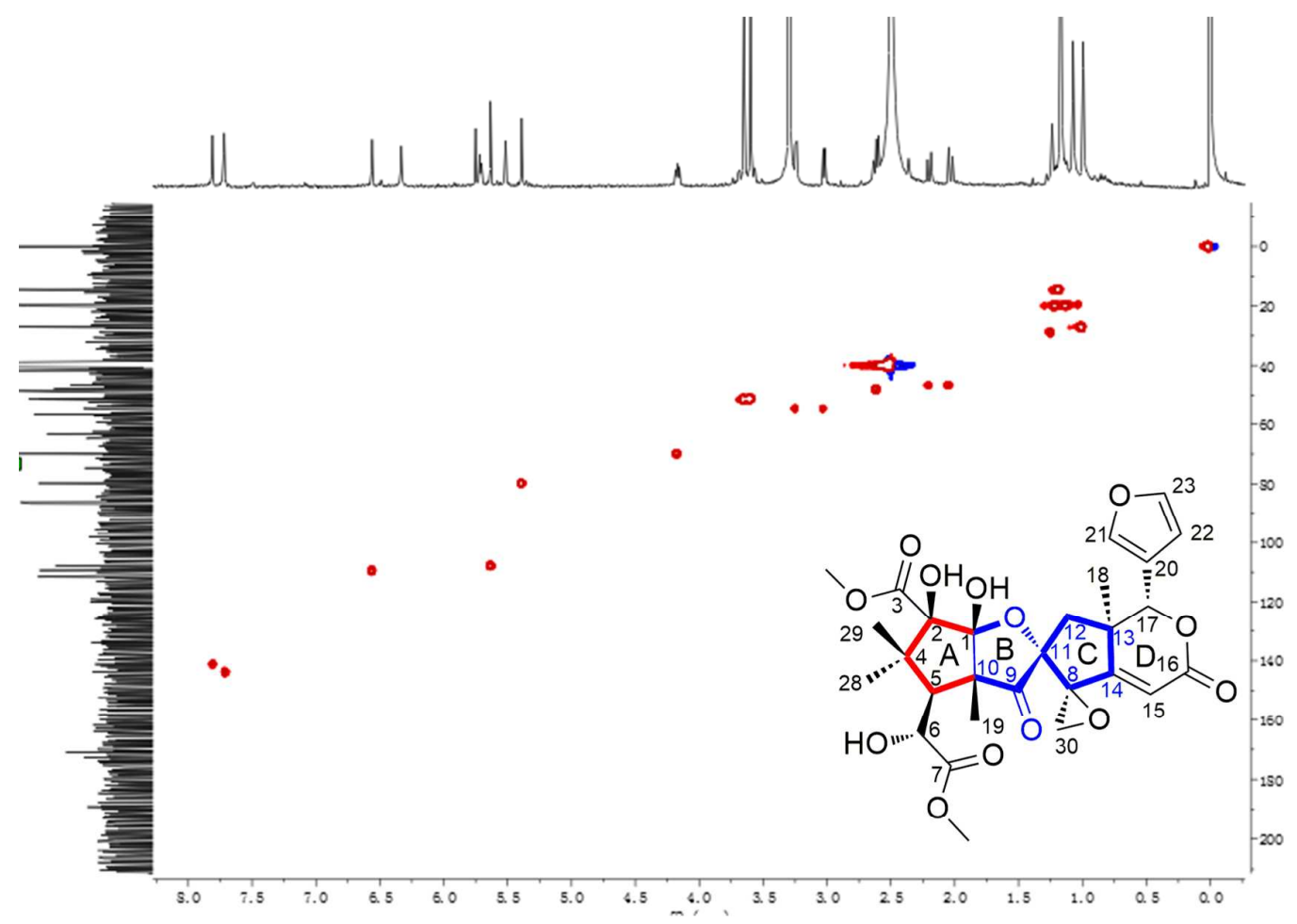

S8. HSQC (DMSO- $\left.d_{6}\right)$ spectrum of $\mathbf{1}$.

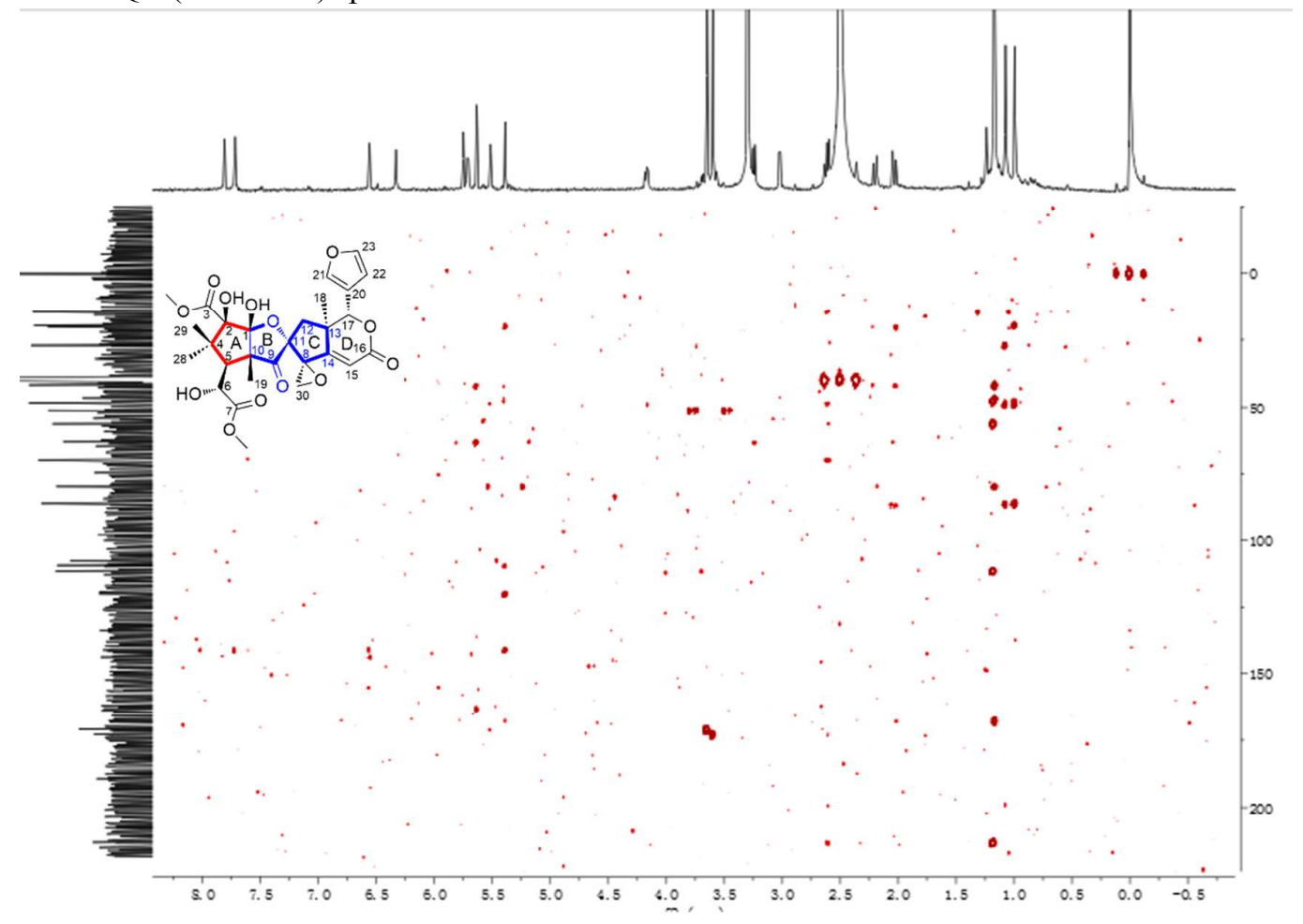

S9. HMBC (DMSO- $d_{6}$ ) spectrum of $\mathbf{1}$. 


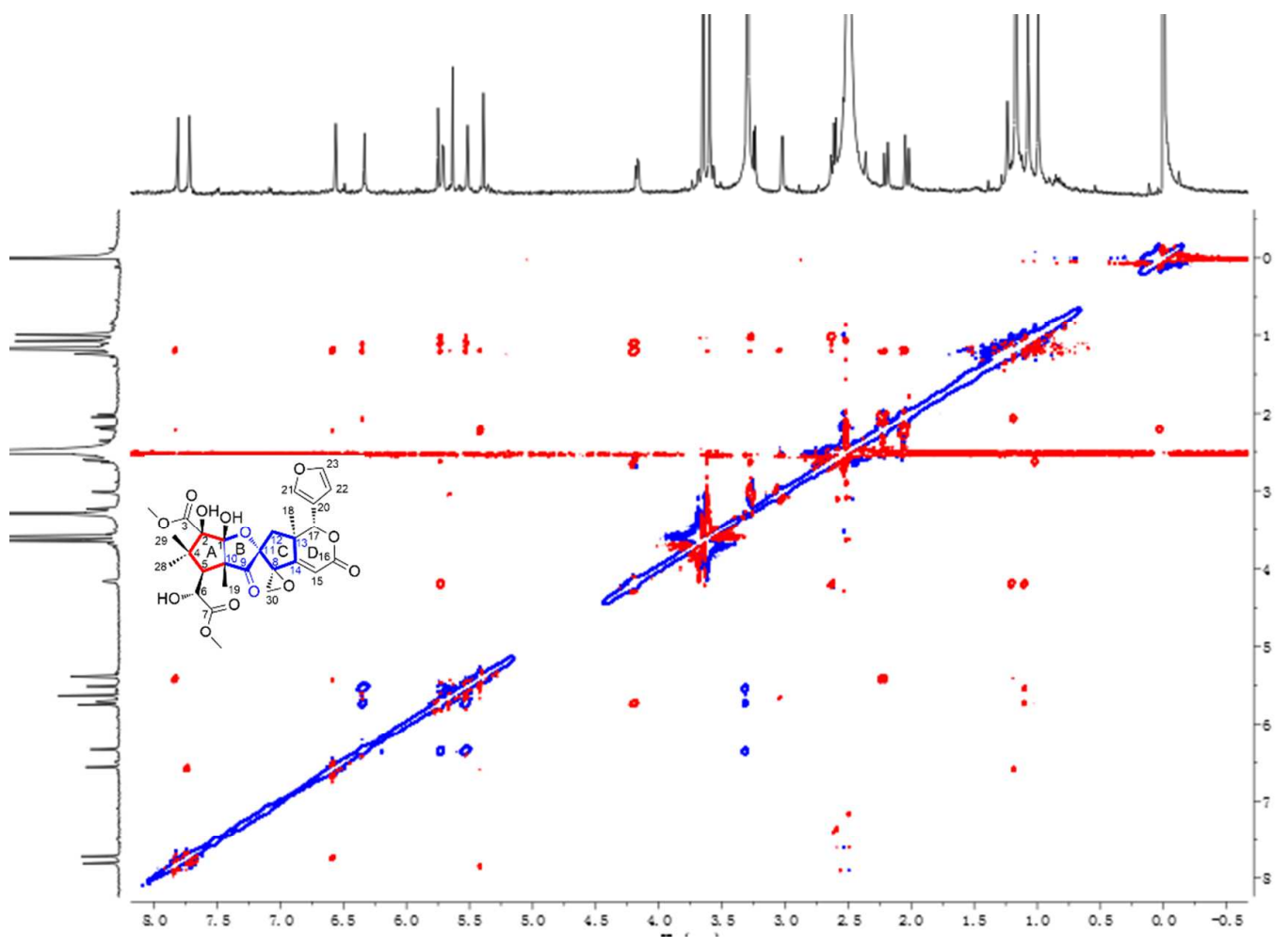

S10. ROESY (DMSO- $d_{6}$ ) spectrum of $\mathbf{1}$. 


\begin{tabular}{llll} 
TCM-CPU & HR-ESI-MS & Display Report \\
\hline Sample Name: & LM-48-1 & Instrument: & Agilent 6520B Q-TOF \\
Acq. Date: & $1201 / 2015$ & Operator: & Administrator \\
\hline
\end{tabular}
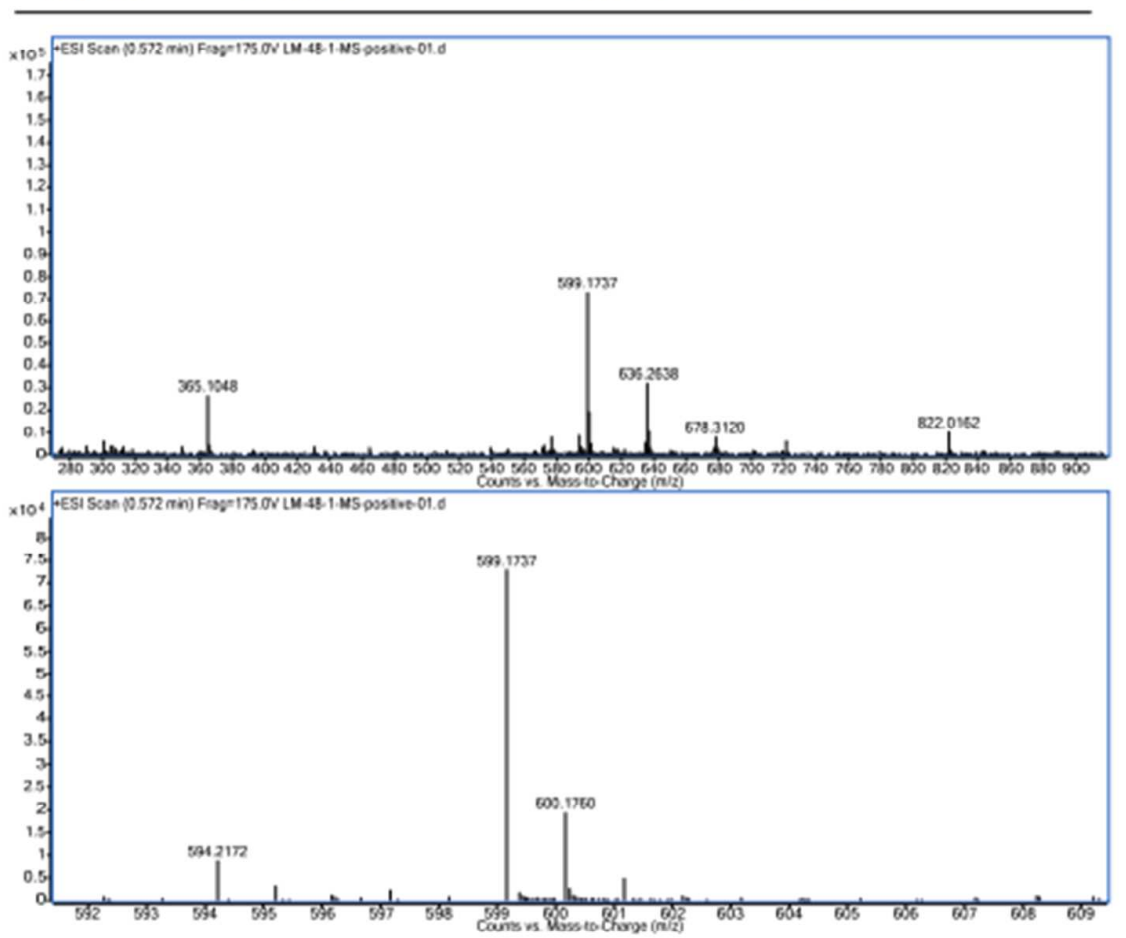

Elemental Composition Calculator

\begin{tabular}{|c|c|c|c|c|c|}
\hline Target $\mathrm{m} / 2$ : & 599.1737 & Result type: & Positive ions & Species: & {$[\mathrm{M}+\mathrm{Na}]^{+}$} \\
\hline \multicolumn{2}{|c|}{ Elements: } & \multicolumn{4}{|c|}{$\mathrm{C}(0-80) ; \mathrm{H}(0-120) ; \mathrm{O}(0-30) ; \mathrm{N}(0-10) ; \mathrm{Na}(0-5)$} \\
\hline \multicolumn{2}{|c|}{ Ion Formula } & \multicolumn{2}{|c|}{ Calcalated $\mathrm{m} / \mathrm{z}$} & \multicolumn{2}{|c|}{ PPM Error } \\
\hline \multicolumn{2}{|c|}{$\mathrm{C} 28 \mathrm{H} 32 \mathrm{NaO} 13$} & & 735 & \multicolumn{2}{|c|}{-0.32} \\
\hline
\end{tabular}

3,5. Agilemt Techmologies

S11. HRESIMS of $\mathbf{1}$. 


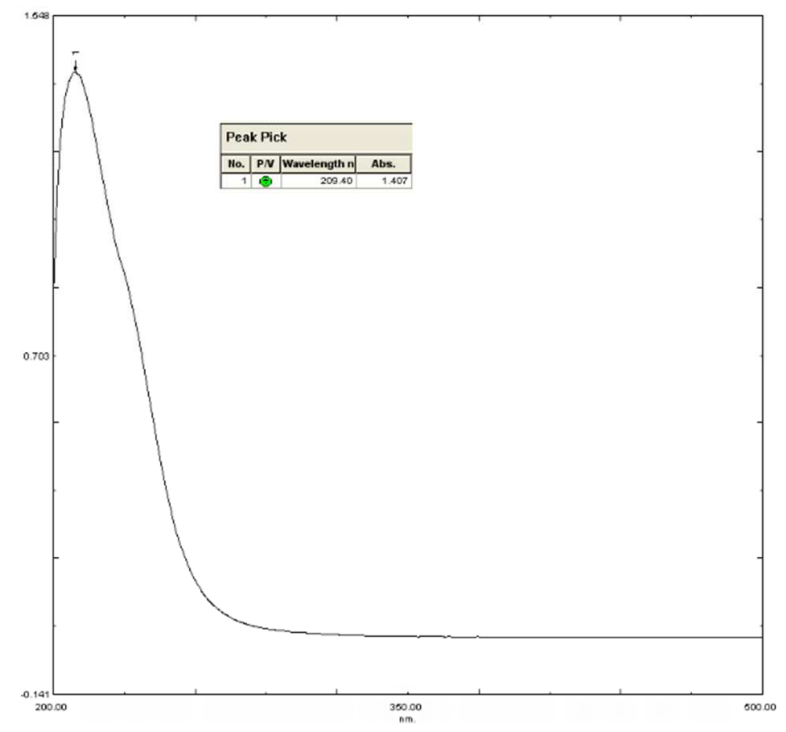

S12. UV spectrum of $\mathbf{1}$.

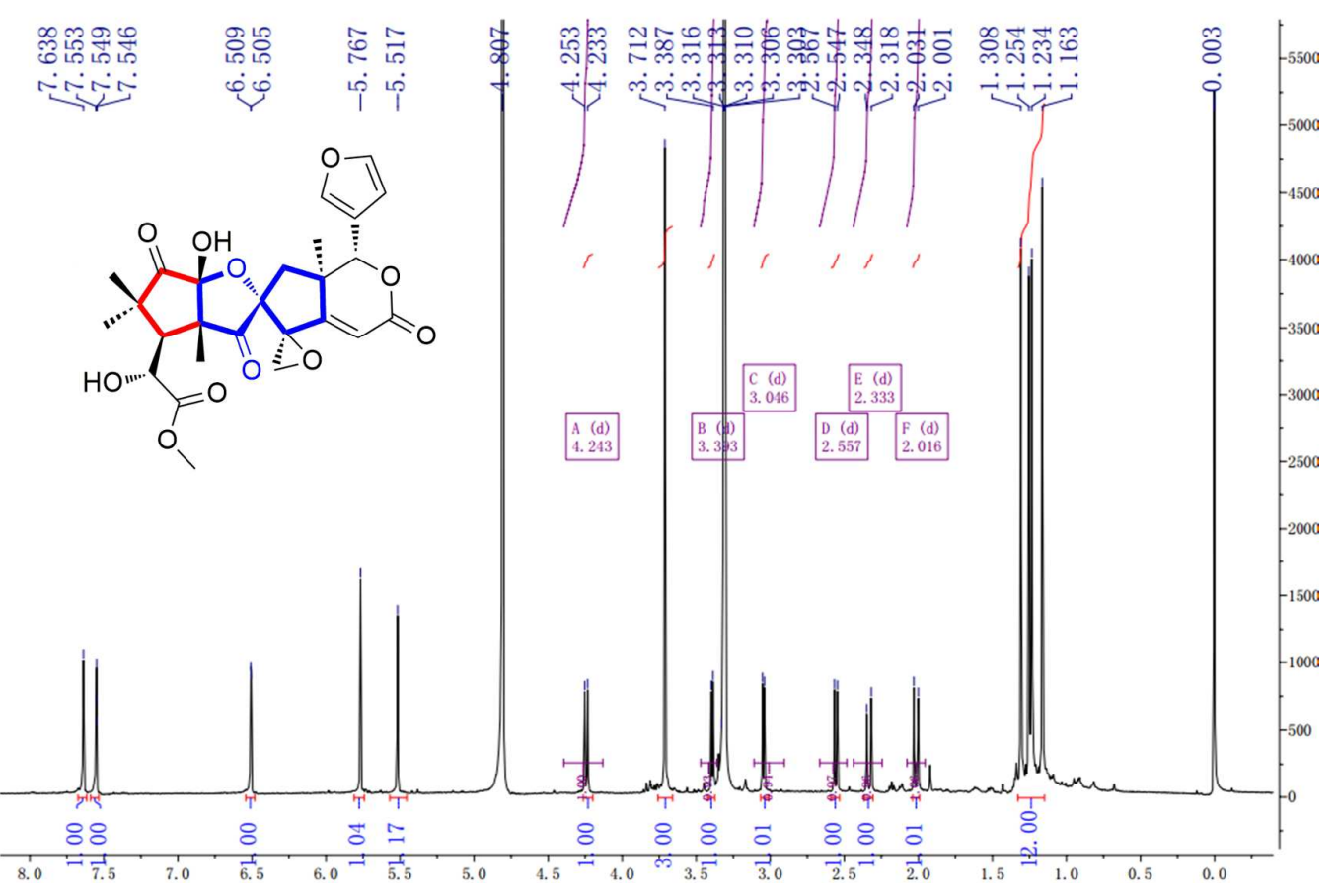

S13. ${ }^{1} \mathrm{H}$ NMR $\left(500 \mathrm{MHz} ; \mathrm{CDCl}_{3}\right)$ spectrum of 2. 


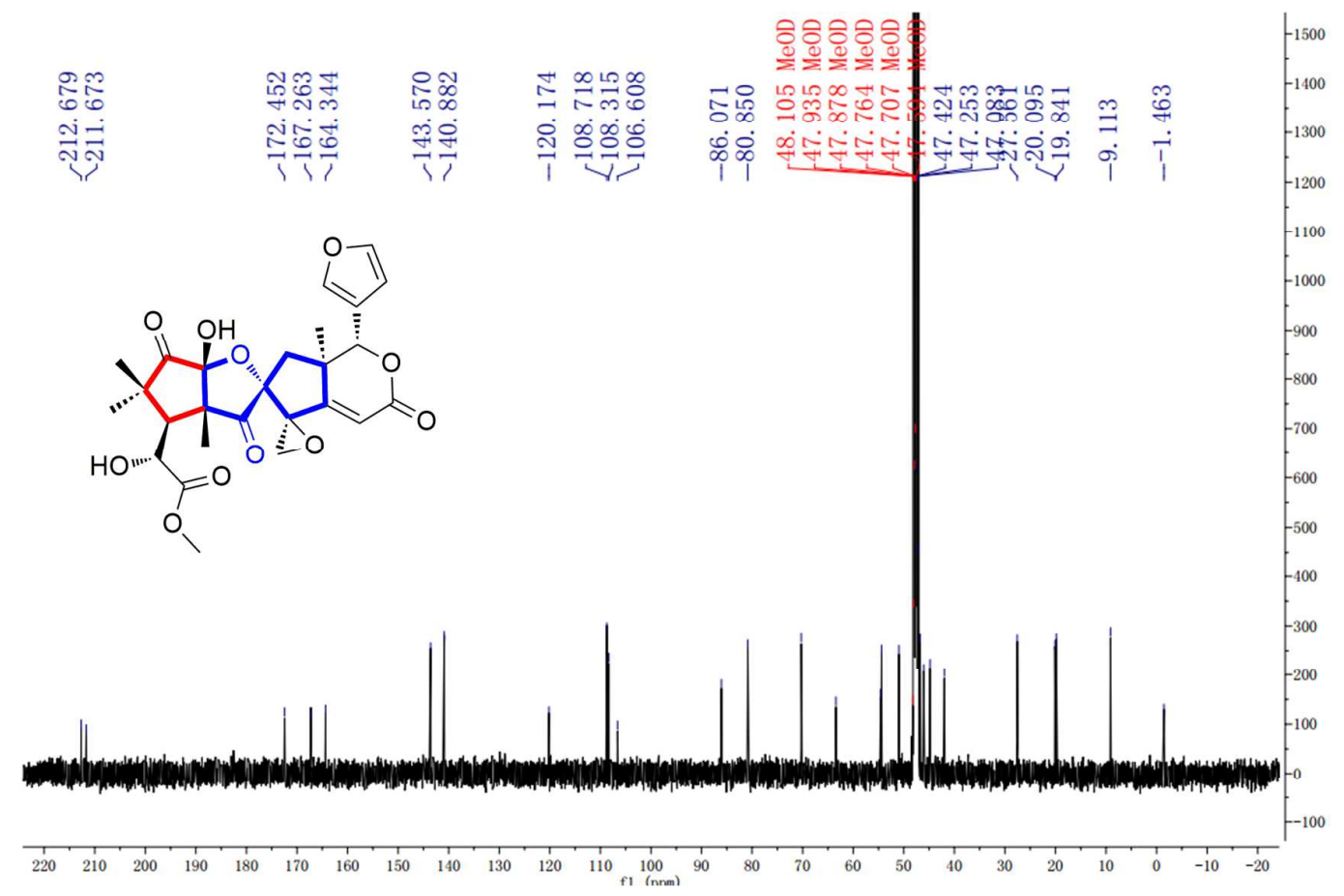

S14. ${ }^{13} \mathrm{C}$ NMR (125 MHz; $\mathrm{CDCl}_{3}$ ) spectrum of 2.

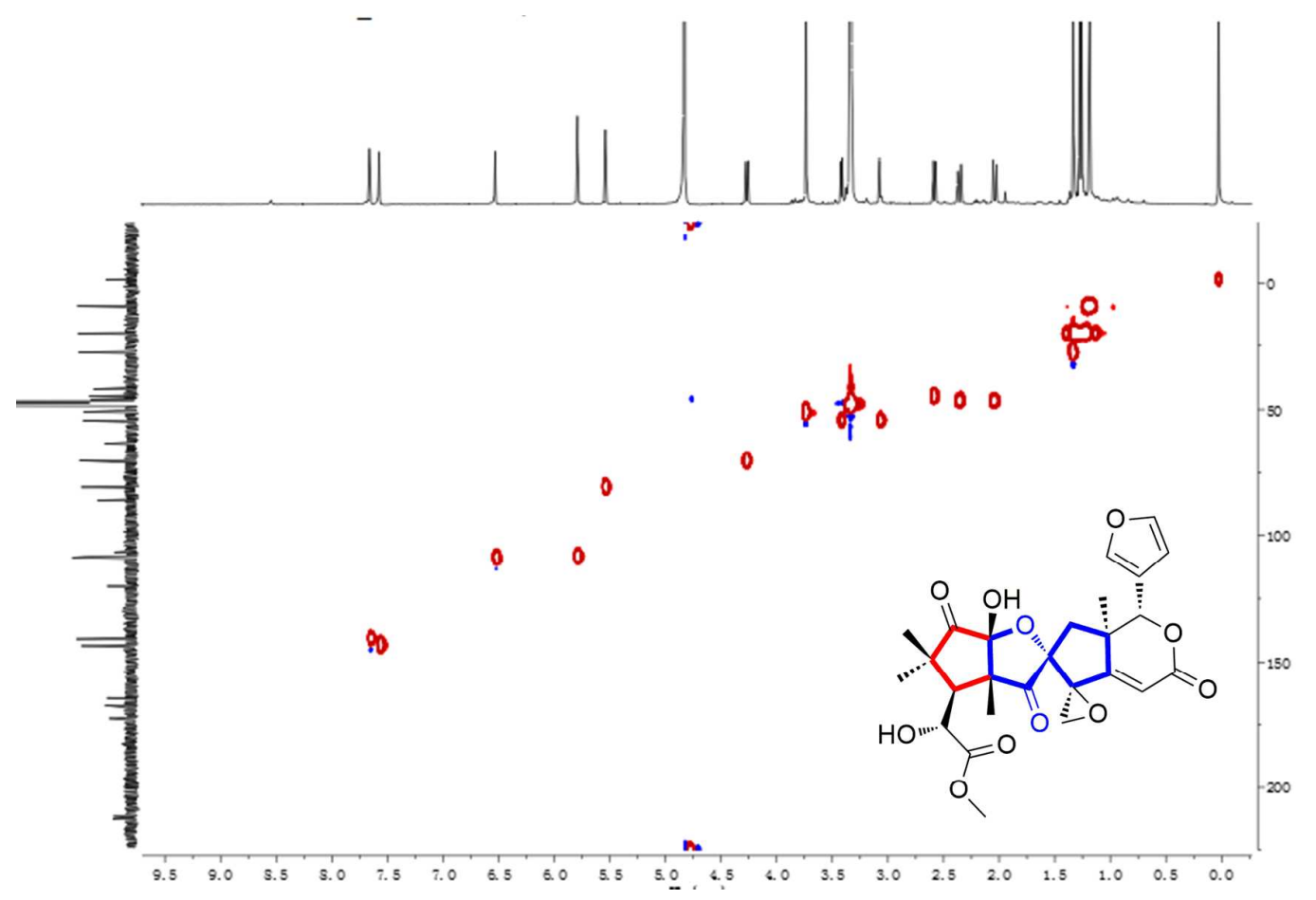

S15. HSQC $\left(\mathrm{CDCl}_{3}\right)$ spectrum of $\mathbf{2}$. 


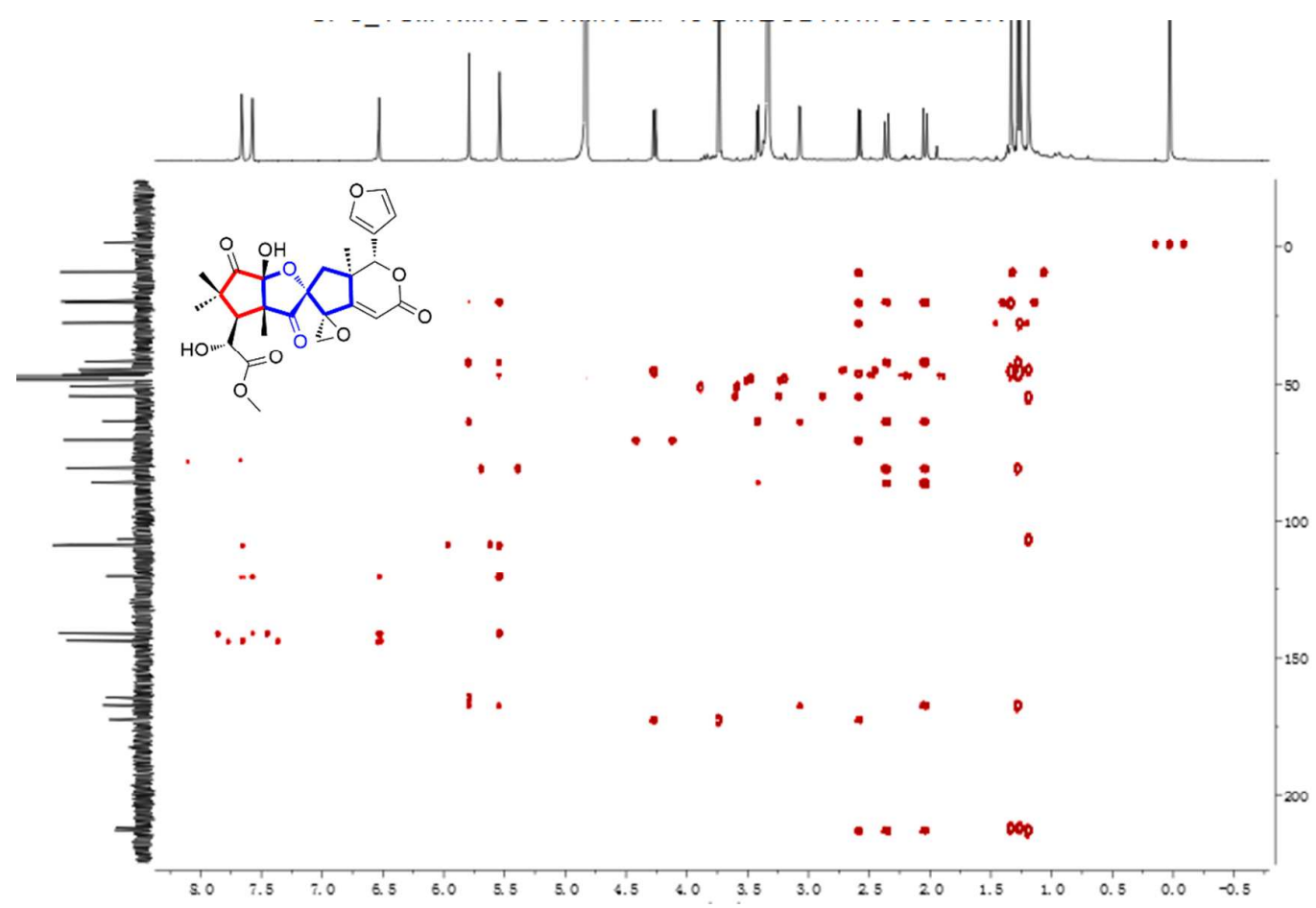

S16. HMBC $\left(\mathrm{CDCl}_{3}\right)$ spectrum of 2.

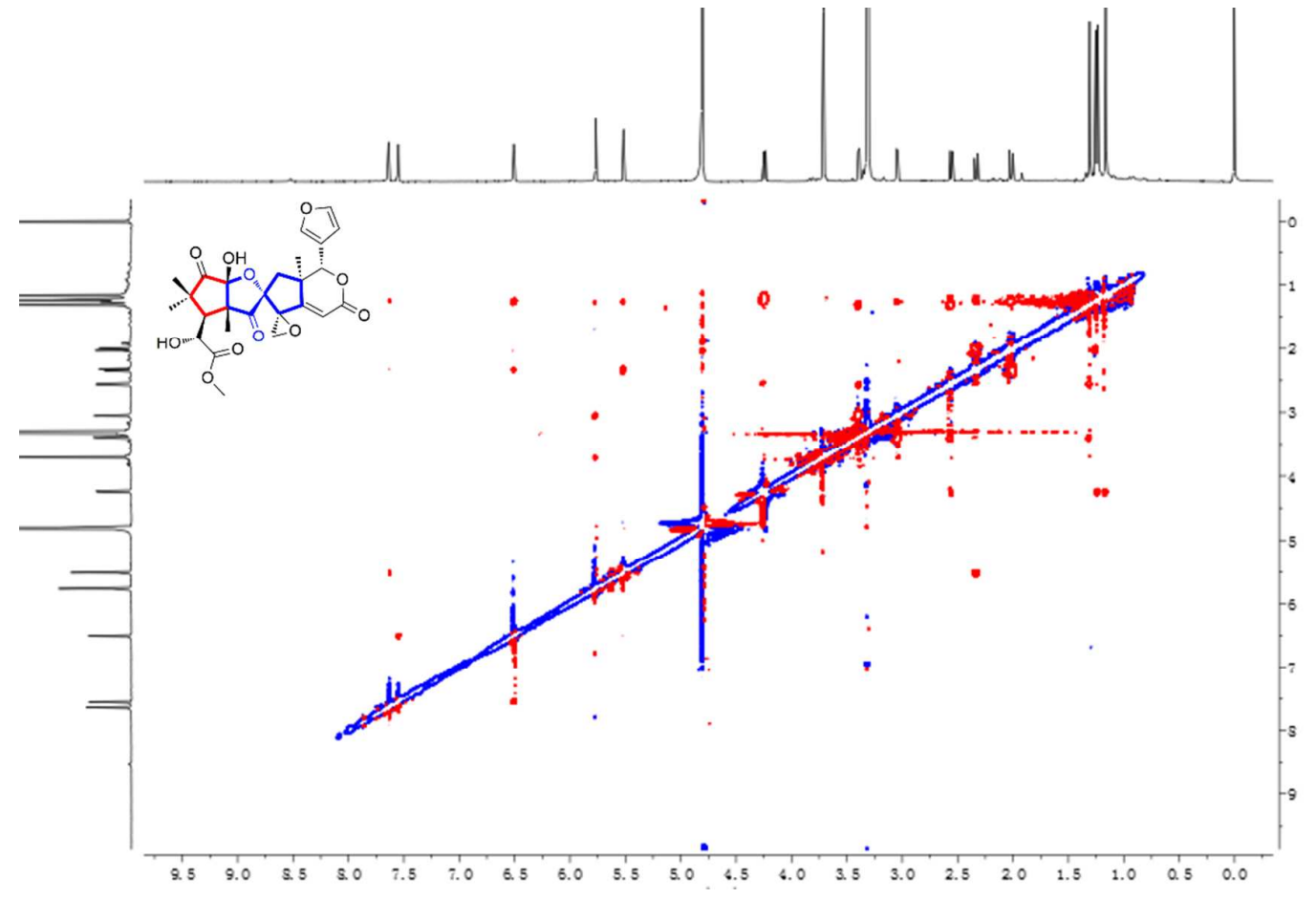

S17. ROESY $\left(\mathrm{CDCl}_{3}\right)$ spectrum of $\mathbf{2}$. 


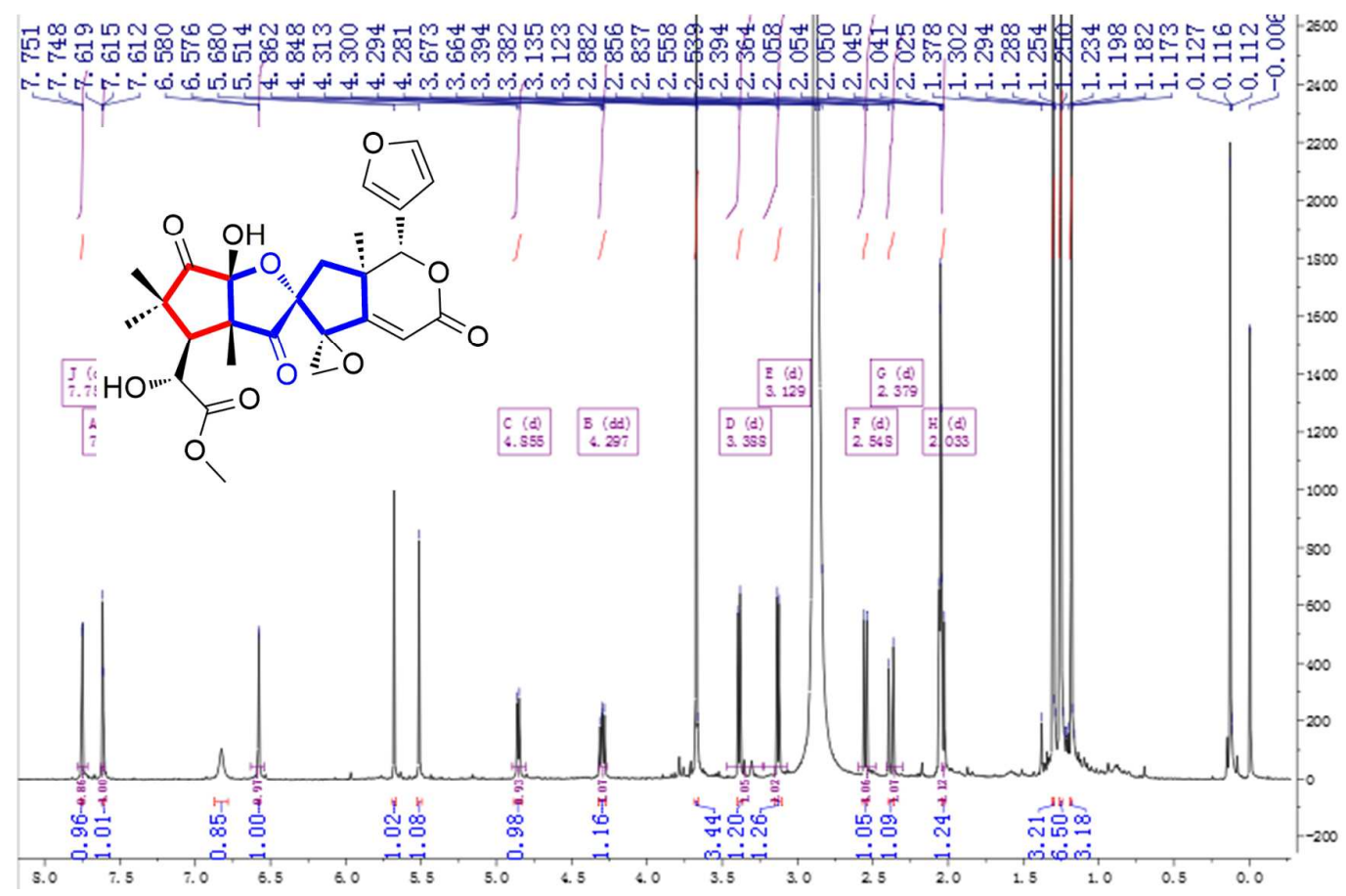

S18. ${ }^{1} \mathrm{H}$ NMR ( $500 \mathrm{MHz}$; Acetone- $d_{6}$ ) spectrum of 2.

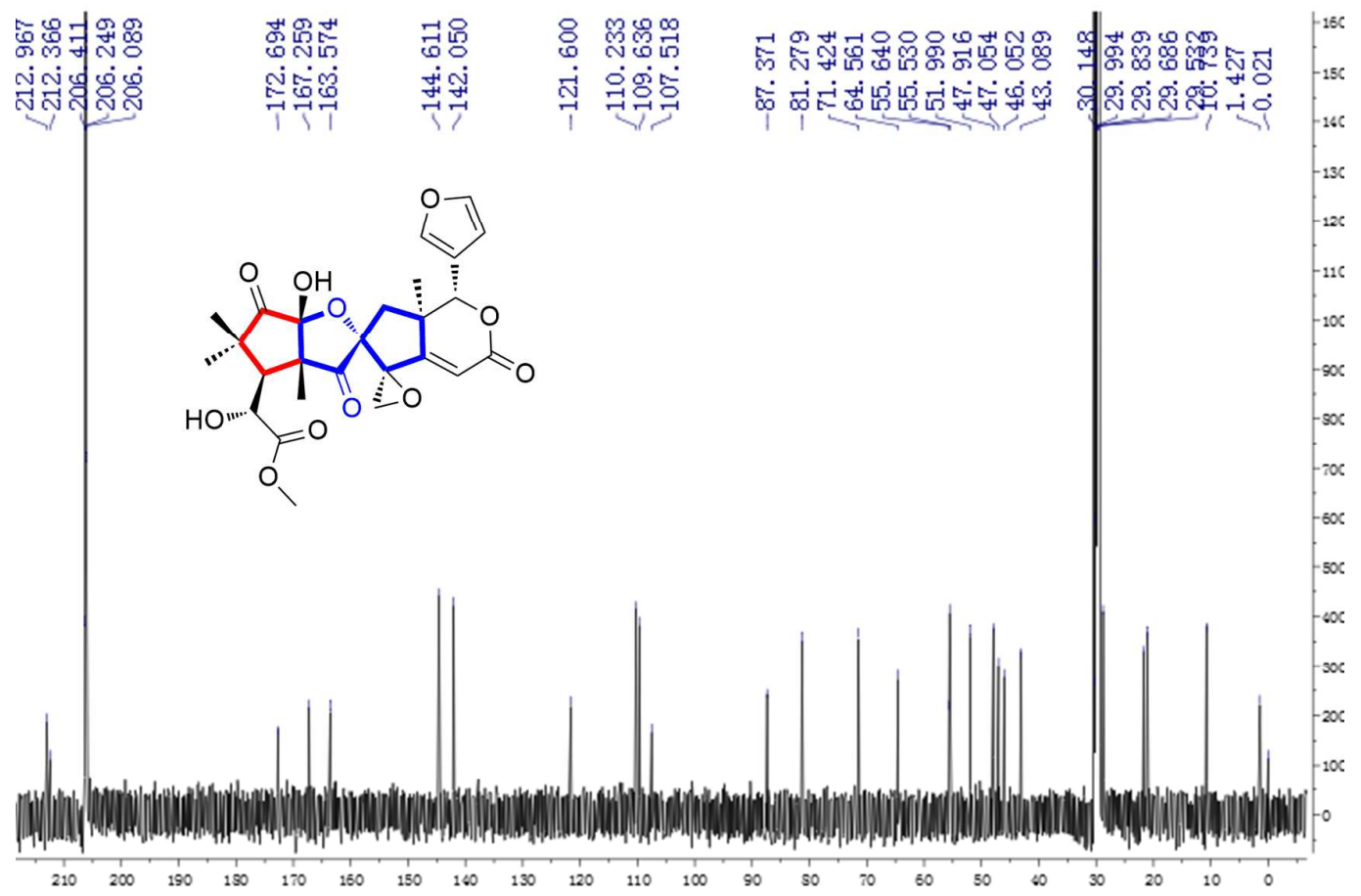

S19. ${ }^{13} \mathrm{C}$ NMR (125 MHz; Acetone- $\left.d_{6}\right)$ spectrum of 2. 


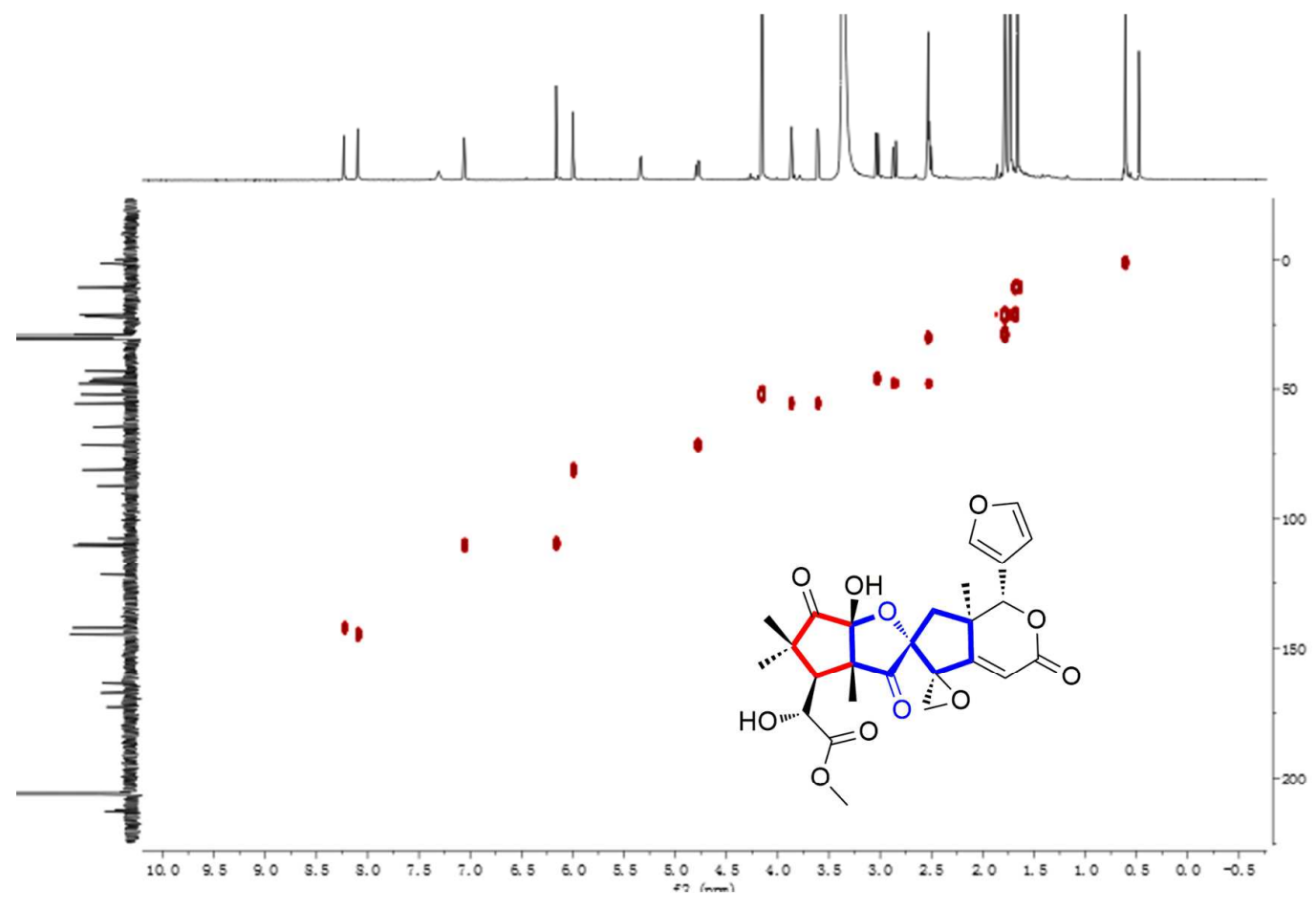

S20. HSQC (Acetone- $d_{6}$ ) spectrum of 2.

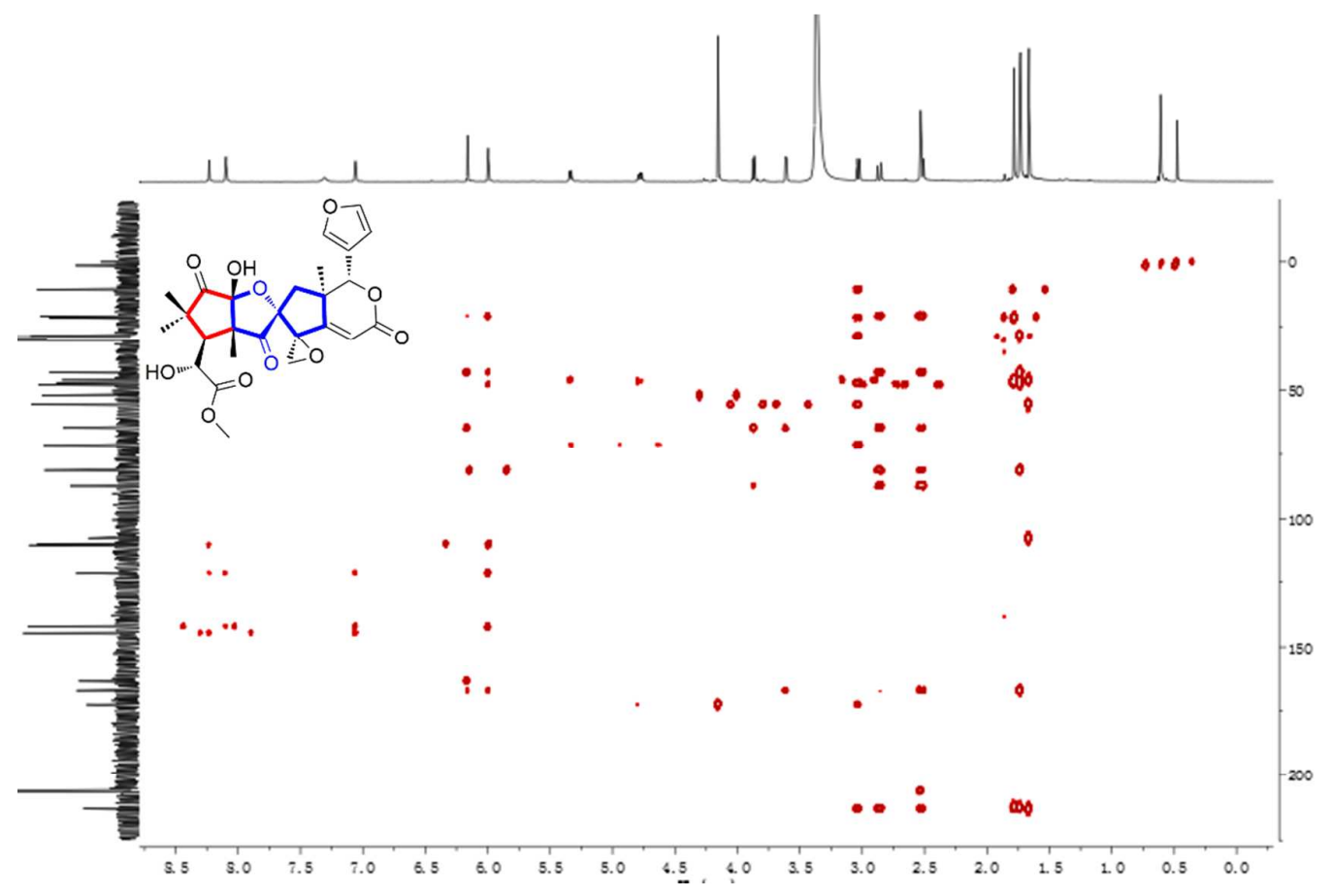

S21. HMBC (Acetone- $d_{6}$ ) spectrum of 2. 


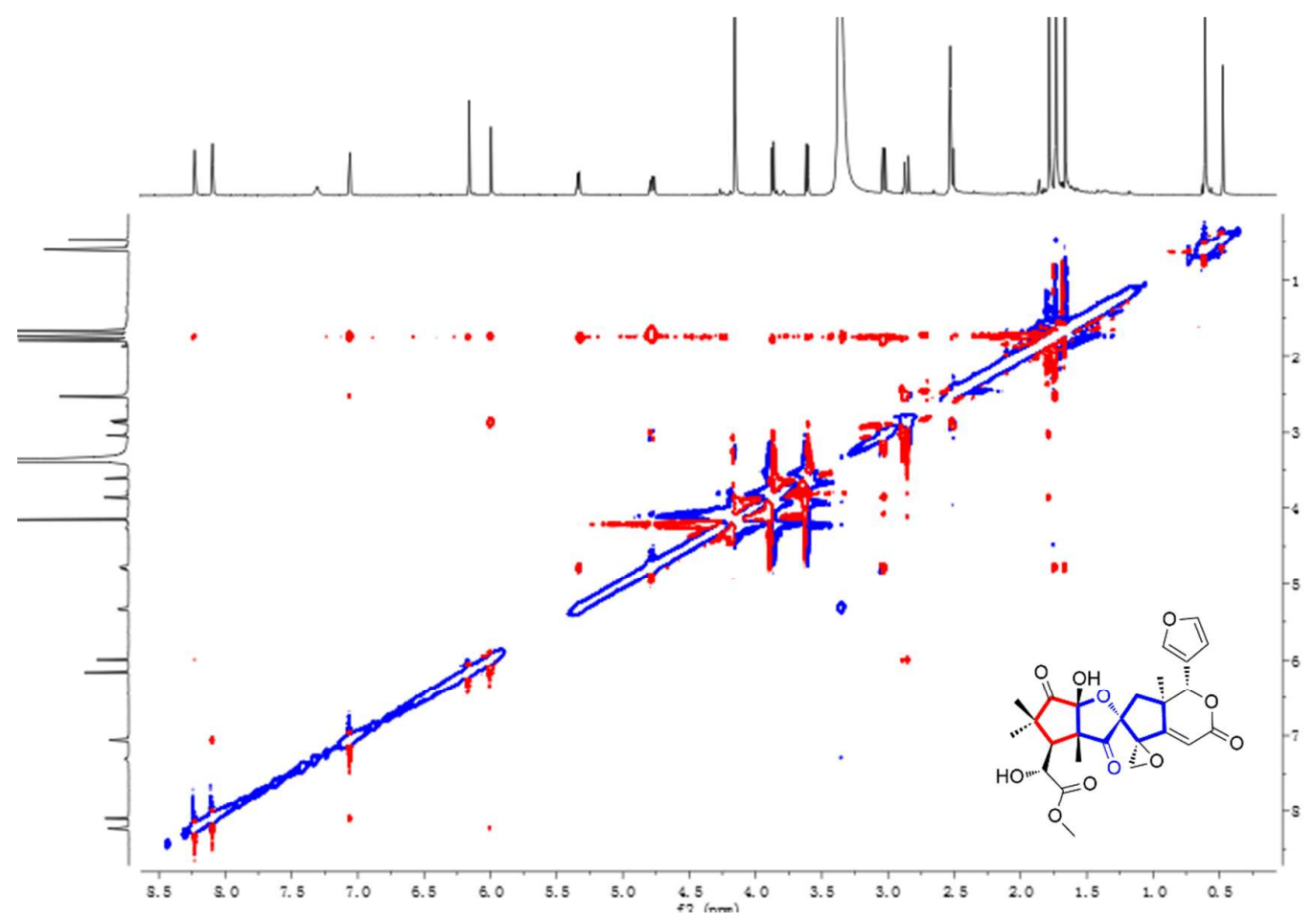

S22. ROESY (Acetone- $d_{6}$ ) spectrum of 2 . 


\section{TCM-CPU HR-ESI-MS Display Report}

\begin{tabular}{llll}
\hline Sample Name: & LM-48-2 & Instrument: & Agilent 6520B Q-TOF \\
Acq. Date: & $09 / 05 / 2015$ & Operator: & Administrator \\
\hline
\end{tabular}
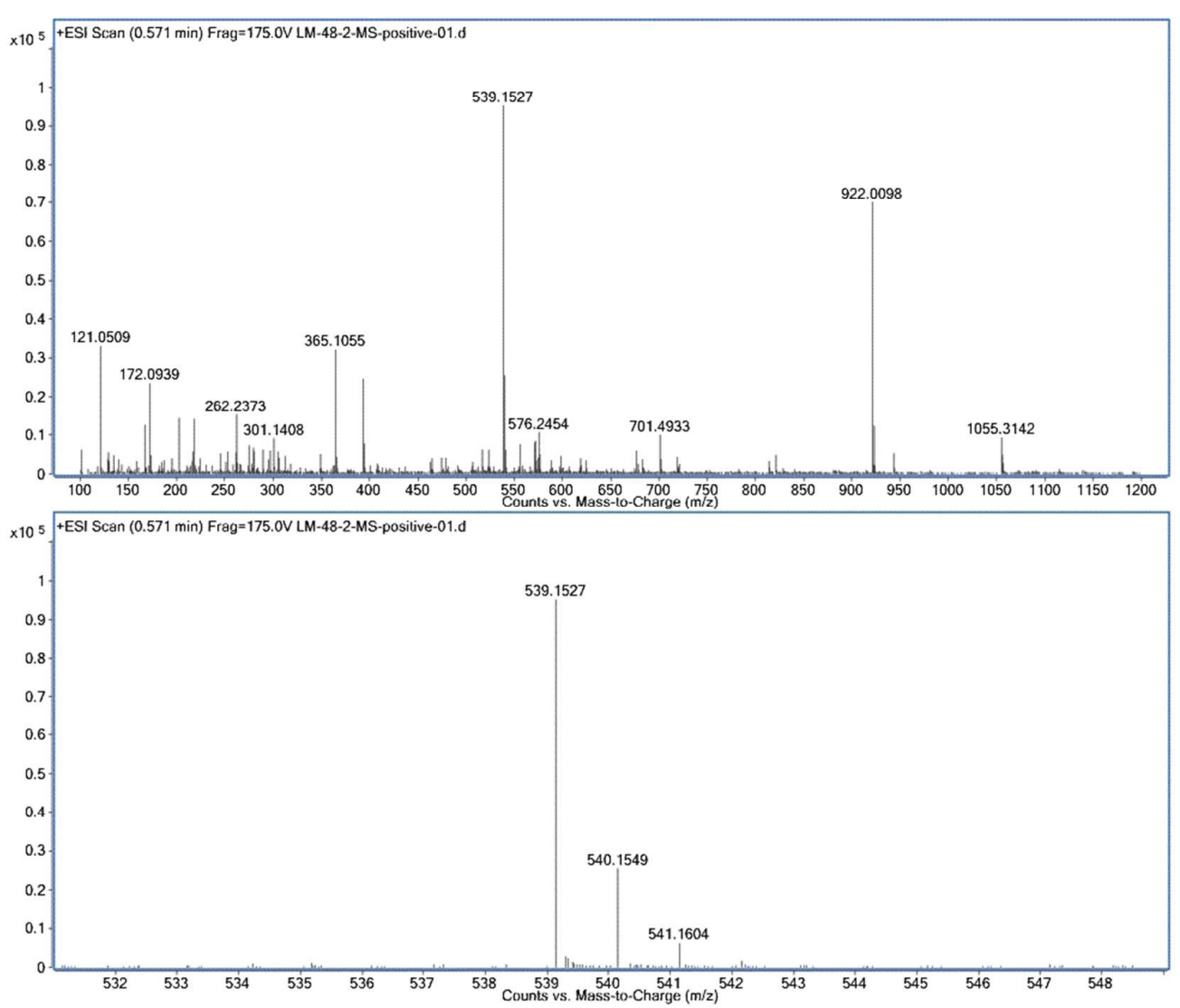

Elemental Composition Calculator

\begin{tabular}{|c|c|c|c|c|c|}
\hline Target $\mathbf{m} / \mathbf{z}$ : & 539.1527 & Result type: & Positive ions & Species: & {$[\mathrm{M}+\mathrm{Na}]^{+}$} \\
\hline \multicolumn{2}{|c|}{ Elements: } & \multicolumn{4}{|c|}{$\mathrm{C}(0-80) ; \mathrm{H}(0-120) ; \mathrm{O}(0-30) ; \mathrm{N}(0-10) ; \mathrm{Na}(0-5)$} \\
\hline \multicolumn{2}{|c|}{ Ion Formula } & \multicolumn{2}{|c|}{ Calcalated $\mathrm{m} / \mathrm{z}$} & \multicolumn{2}{|c|}{ PPM Error } \\
\hline \multicolumn{2}{|c|}{$\mathrm{C} 26 \mathrm{H} 28 \mathrm{NaO} 11$} & \multicolumn{2}{|c|}{539.1524} & \multicolumn{2}{|c|}{-0.58} \\
\hline
\end{tabular}

Agilent Technologies

\section{S23. HRESIMS of 2.}




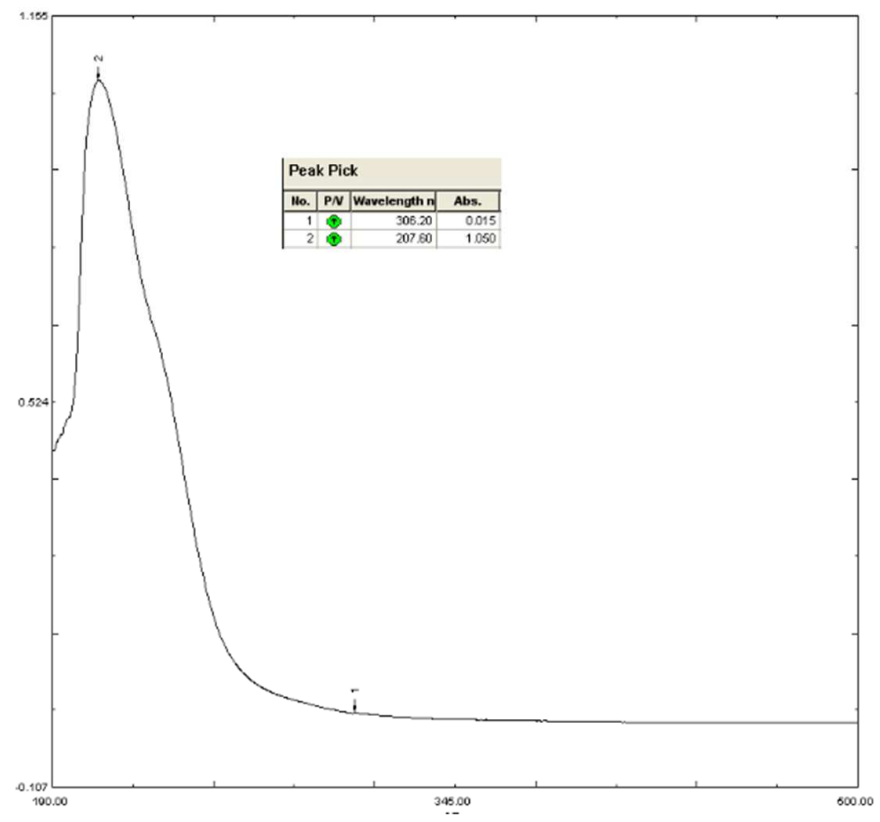

S24. UV spectrum of 2. 
Table 1. ${ }^{1} \mathrm{H}(500 \mathrm{MHz})$ and ${ }^{13} \mathrm{C}(125 \mathrm{MHz})$ NMR Data of Compounds 1-2 in methanol- $d_{4}$.

\begin{tabular}{|c|c|c|c|c|c|c|c|c|c|}
\hline \multirow{2}{*}{ No. } & \multicolumn{2}{|l|}{1} & \multicolumn{2}{|l|}{2} & \multirow{2}{*}{ No. } & \multicolumn{2}{|c|}{1} & \multicolumn{2}{|c|}{2} \\
\hline & $\delta_{\mathrm{H}}$, milt & $\delta_{\mathrm{C}}$ & $\delta_{\mathrm{H}}$, milt & $\delta_{\mathrm{C}}$ & & $\delta_{\mathrm{H}}$, milt & $\delta_{\mathrm{C}}$ & $\delta_{\mathrm{H}}$, milt & $\delta_{\mathrm{C}}$ \\
\hline 1 & & 113.2 & & 106.6 & 15 & $5.77 \mathrm{~s}$ & 109.2 & $5.77 \mathrm{~s}$ & 108.3 \\
\hline 2 & & 87.7 & & 211.7 & 16 & & 165.9 & & 164.3 \\
\hline 3 & & 172.5 & & & 17 & $5.49 \mathrm{~s}$ & 82.2 & $5.52 \mathrm{~s}$ & 80.9 \\
\hline 4 & & 49.5 & & 46.1 & 18 & $1.28 \mathrm{~s}$ & 21.4 & $1.25 \mathrm{~s}$ & 19.8 \\
\hline 5 & $2.75 \mathrm{~d}(8.5)$ & 49.4 & $2.56 \mathrm{~d}(8.5)$ & 44.8 & 19 & $1.31 \mathrm{~s}$ & 14.2 & $1.23 \mathrm{~s}$ & 9.1 \\
\hline 6 & $4.29 \mathrm{~d}(8.5)$ & 71.8 & $4.24 \mathrm{~d}(8.5)$ & 70.3 & 20 & & 121.6 & & 120.2 \\
\hline 7 & & 174.7 & & 172.5 & 21 & $7.58 \mathrm{~s}$ & 142.3 & $7.64 \mathrm{~s}$ & 140.9 \\
\hline 8 & & 64.4 & & 63.4 & 22 & $6.52 \mathrm{~s}$ & 110.2 & $6.52 \mathrm{~s}$ & 108.7 \\
\hline 9 & & 215.4 & & 212.7 & 23 & $7.65 \mathrm{~s}$ & 145.0 & $7.55 \mathrm{~s}$ & 143.6 \\
\hline 10 & & 58.8 & & 54.4 & 28 & $1.25 \mathrm{~s}$ & 20.2 & $1.31 \mathrm{~s}$ & 20.1 \\
\hline 11 & & 87.5 & & 86.1 & 29 & $1.16 \mathrm{~s}$ & 29.0 & $1.16 \mathrm{~s}$ & 27.6 \\
\hline & $2.31 \mathrm{~d}(15.0)$ & & $2.33 \mathrm{~d}(15.0)$ & & & $3.47 \mathrm{~d}(6.5)$ & & $3.39 \mathrm{~d}(6.5)$ & \\
\hline 12 & $2.15 \mathrm{~d}(15.0)$ & $47 \cdot 7$ & $2.02 \mathrm{~d}(15.0)$ & 46.8 & 30 & $2.99 \mathrm{~d}(6.5)$ & 55.7 & $3.05 \mathrm{~d}(6.5)$ & 54.6 \\
\hline 13 & & 42.9 & & 42.0 & 3-OMe & $3.79 \mathrm{~s}$ & 52.4 & & \\
\hline 14 & & 169.4 & & 167.3 & 7-OMe & $3.73 \mathrm{~s}$ & 52.4 & $3.71 \mathrm{~s}$ & 51.0 \\
\hline
\end{tabular}

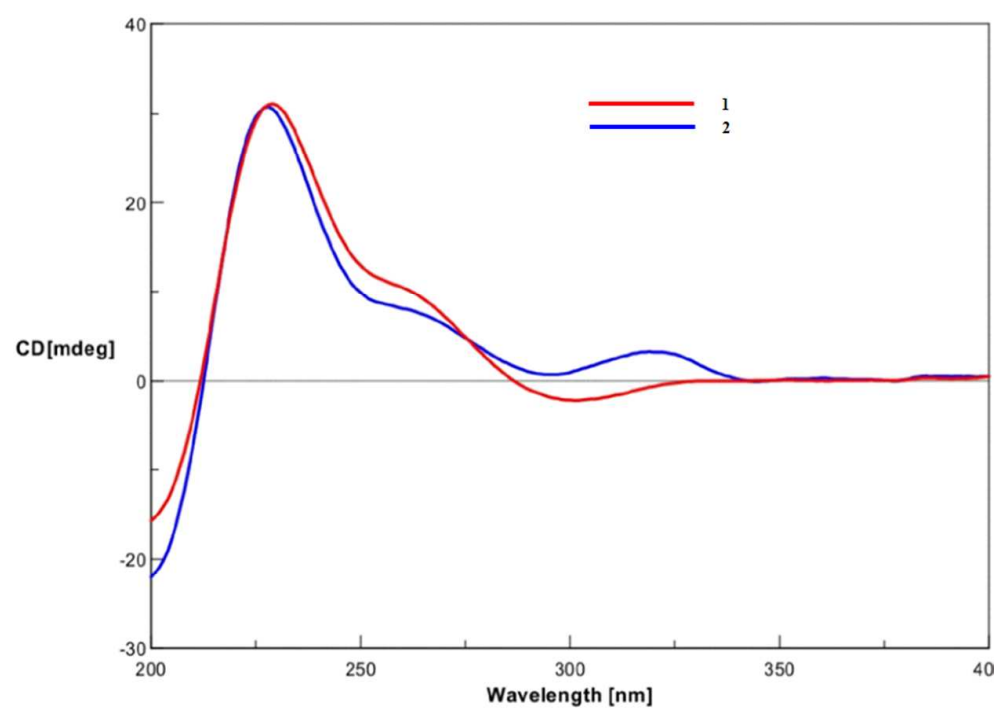

S26 ECD spectra of 1 and $2(\mathrm{MeOH})$. 


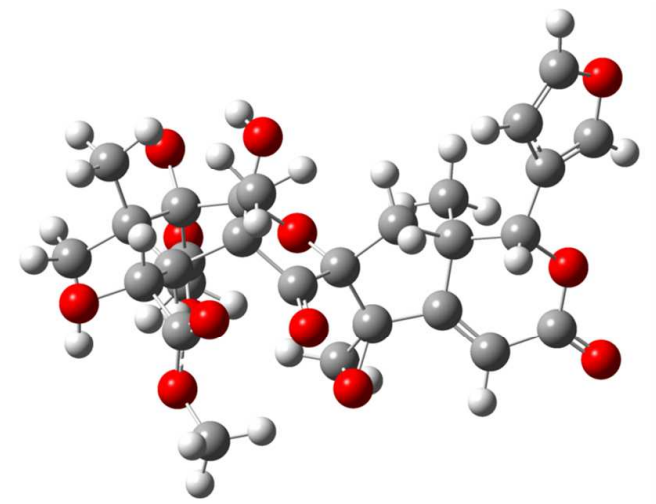

S27 Selected conformer for the calculation of ECD data of $\mathbf{1}$ (in $\mathrm{MeOH})$.

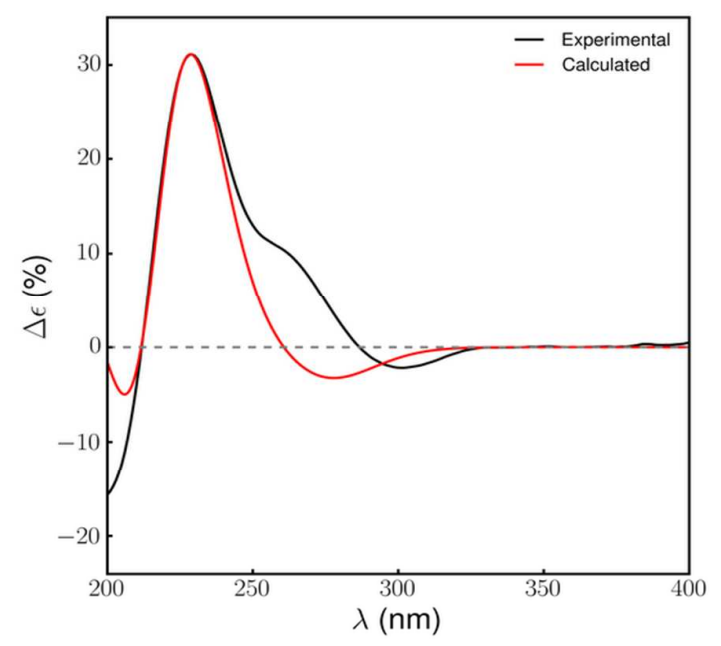

S28. Calculated ECD and experimental ECD spectra of $\mathbf{1}$.

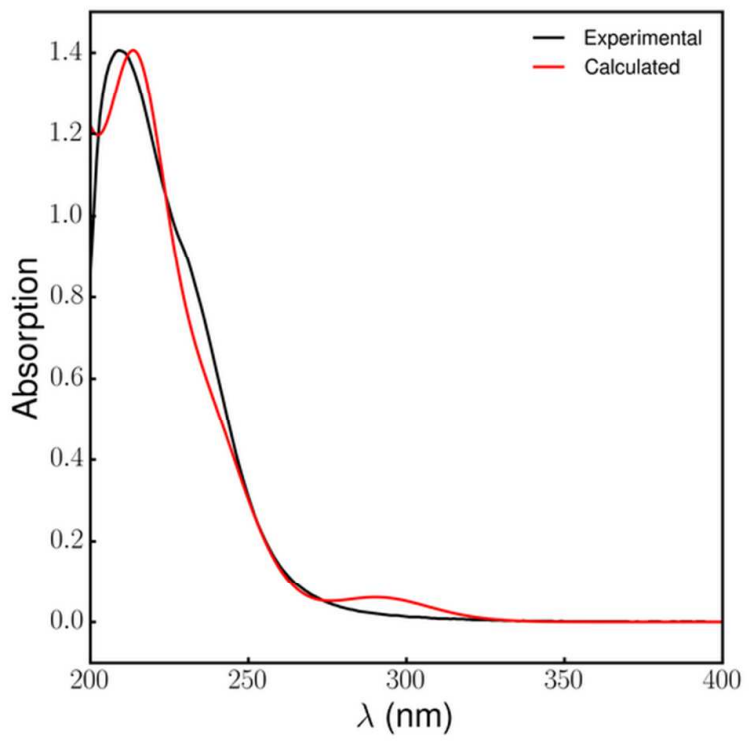

S29. Calculated UV and experimental UV spectra spectrum of $\mathbf{1}$. 


\begin{tabular}{ccc}
\hline No. & Energie $(\mathrm{kcal} / \mathrm{mol})$ & $\%$ \\
\hline 1 & 175.95830 & 100 \\
2 & 186.72839 & 0 \\
3 & 186.97026 & 0 \\
4 & 191.03214 & 0 \\
5 & 191.28782 & 0 \\
6 & 194.55832 & 0 \\
7 & 195.53930 & 0 \\
8 & 196.72874 & 0 \\
9 & 196.81270 & 0 \\
10 & 197.15142 & 0 \\
\hline
\end{tabular}

S30. Energies of the conformers with Boltzmann distribution over 1\%.

\begin{tabular}{cccc}
\hline NO. & $\begin{array}{c}\text { Energy } \\
(\text { A.U. })\end{array}$ & $\begin{array}{c}\text { Energy } \\
(\mathrm{kcal} / \mathrm{mol})\end{array}$ & $\begin{array}{c}\text { Number of } \\
\text { imaginary frequencies }\end{array}$ \\
\hline 1 & -2064.64510956 & -1295585.45272510 & 0 \\
\hline
\end{tabular}

S31 Energies and vibrational analysis of compounds 1. 